\title{
ACUPUNTURA NA PREVENÇÃO, TRATAMENTO DE LESÕES E MELHORA DA PERFORMANCE EM ATLETAS: REVISÃO DE LITERATURA
}

\section{ARTIGO DE REVISÃO}

JUNIOR, Julio Cesar Dias ${ }^{1}$

Junior, Julio Cesar Dias. Acupuntura na prevenção, tratamento de lesões e melhora da performance em atletas: Revisão de literatura. Revista Científica Multidisciplinar Núcleo do Conhecimento. Ano 04, Ed. 10, Vol. 10, pp. 59-98. Outubro de 2019. ISSN: 2448-0959, Link de acesso: https://www.nucleodoconhecimento.com.br/saude/acupuntura-na-prevencao

\section{RESUMO}

Estudos demonstraram que acupuntura melhora a performance física em atletas profissionais, porém o grande problema são as lesões esportivas, que podem deixálos afastados das atividades por longos períodos. O estudo realizou uma revisão de literatura, buscando a eficácia da técnica na prevenção, melhora da performance e no

${ }^{1}$ Graduação em Fisioterapia pelo Centro Universitário de Araraquara - UNIARA - 2005 (Araraquara-SP);Pós Graduação lato sensu em Fisioterapia Ortopédica e Traumatológica pelo Instituto Cohen - Ortopedia, Reabilitação e Medicina Esportiva 2006 (São Paulo-SP)Formação em Terapia Manual Osteopática pelo Instituto Cefisa - 2008 (Araraquara-SP); Aprimoramento Profissional em Reeducação Postural Global e Reprogramação Sensório Motora - RPG/RSM pelo Instituto Paulista de Estudos Sistêmicos - IPES - 2010 (Ribeirão Preto-SP); Pós Graduação lato sensu em Acupuntura Sistêmica pelo Instituto Paulista de Estudos Sistêmicos - IPES - 2013 (Ribeirão Preto-SP); Pós Graduação stricto sensu Mestrado em Desenvolvimento Territorial e Meio Ambiente pelo Centro Universitário de Araraquara - UNIARA - 2016 (Araraquara - SP); Aprimoramento Profissional em Pilates Clínico e Funcional pelo Instituto Paulista de Estudos Sistêmicos - IPES - 2016 (Ribeirão Preto-SP). 
tratamento de lesões. Alguns autores exemplificam e esclarecem o processo da neurofisiologia da dor e a maneira, na qual, a acupuntura pode intervir neste problema, outros, desenvolvem e aplicam protocolos para atingir uma melhora do desempenho, tratamento de afecções e prevenção da lesão. Dentre os resultados foram encontrados oitenta e nove artigos sobre o tema, onde: vinte dois relataram o tratamento de lesões e trinta e sete a prevenção e melhora do desempenho atlético, direcionando a aplicação uma vez na semana, de 20 - 30 minutos, apresentando resultados satisfatórios para os dados analisados. Com base nesta literatura e na prática baseada em evidências pode-se concluir que acupuntura é uma ótima intervenção para se atingir esses objetivos dentro da área do desporto.

Palavras Chave: Acupuntura, lesões, dor, performance.

\section{INTRODUÇÃO}

Há vários milênios a acupuntura vem sendo utilizada como forma de prevenção e tratamento de diversas afecções do organismo. Esta técnica da medicina chinesa manipulava agulhas de pedras e espinhas de peixes por toda a idade da pedra (3000 anos aC). ${ }^{1,2} \mathrm{O}$ Clássico Imperador Amarelo: Huang Di Nei Jing, constituiu um dos registros mais antigos da Medicina Tradicional Chinesa (MTC), integrando até os dias atuais as bases filosóficas, que conceitua o equilíbrio do universo e da natureza, que na sua visão (Chinesa), energia é denominada Chi ou Qi. Este fator, possuí dois princípios antagônicos que se completam e tendem estar em equilíbrio, mesmo estando sob influência do universo, denominados Yin e Yang. ${ }^{3}$

A acupuntura é definida como a harmonização do indivíduo com o meio ambiente em que ele se encontra, não se tratando apenas, de inserir agulhas e sanar o problema da doença, mas, atingir o ideal da prevenção de várias patologias. ${ }^{4}{ }^{5}$ É um procedimento realizado com objetivo terapêutico, não é tóxico, sem utilização de elementos químicos, com efeitos secundários mínimos, embora seja capaz de liberar substâncias endógenas como os neurotransmissores. 4, 6,7,8,9 
A intervenção é estimular os acupontos para alcançar o efeito terapêutico desejado e atingir a homeostase do organismo. Muitas pesquisas exemplificam os efeitos da teoria neural não opióide (inibe impulsos nervosos atuando no sistema nervoso periférico e central); teoria humoral (estimula liberação de opiódes endógenos, outros hormônios e neurotransmissores). ${ }^{10,11}$ A propósito no controle da dor, a associação de agulhas com a corrente elétrica, denominada eletroacupuntura, potencializa e apresenta benefícios na prática clínica, além de serem empregadas também como: acupuntura auricular; crâniopuntura; moxabustão; ventosas; acupuntura a laser. 3, 10

Nos esportes, o uso de tecnologia em busca de melhores resultados continua em crescimento, superando os limites do corpo humano. Várias terapias naturais ou integrativas, são estudadas como fonte de terapia complementar para melhoramento das condições atléticas. Apesar do números de estudos serem escassos, a aceitação da acupuntura ainda é muito curiosa, uma vez que muitos indivíduos ainda duvidam das provas científicas. ${ }^{9}$ Porém vem aumentando a sua utilização no meio esportivo, atuando no tratamento da dor e de lesões atléticas, acelerando o processo de recuperação do indivíduo. Outra questão apresentada é a intervenção eficaz na melhora do desempenho físico e na prevenção de lesão de atletas amadores e profissionais. ${ }^{12,13,14}$

\section{OBJETIVO}

O objetivo deste trabalho foi realizar um levantamento bibliográfico da utilização da acupuntura na prevenção, na melhora da performance atlética e no tratamento de lesões em várias modalidades esportivas.

\section{METODOLOGIA}

Foi realizado um levantamento bibliográfico nas bases de dados Scielo, Google Acadêmico, e Scoopus, para obtenção de informações sobre: acupuntura na prevenção, na melhora da performance e no tratamento de lesões esportivas. Foi utilizado o cruzamento das seguintes palavras chaves: acupuntura; acupuntura e dor; 
acupuntura na prevenção; lesão esportiva e acupuntura; acupuntura e melhora da performance atlética; tratamento de lesões e acupuntura.

Para delimitar o recorte deste estudo, realizou-se uma triagem inicial entre os inúmeros artigos encontrados, totalizando 89 manuscritos, selecionando 22 que abordavam o assunto acupuntura no tratamento de lesões e 37 abordando a prevenção de lesões esportivas e melhora do desempenho atlético. Com base nessa análise, cabe ressaltar que de todos os estudos encontrados primariamente, o universo da pesquisa compreendeu 59 artigos publicados em periódicos científicos, anais de congressos, livros, sites, os quais no título, no resumo ou nas palavras chave apresentaram as terminologias utilizadas durante a pesquisa.

\section{RESULTADOS E DISCUSSÃO}

Nesta busca resultou em vários artigos (Gráfico 1; Tabela 1), tendo sido realizada de forma isolada através das palavras chaves.

Gráfico 1: número total de artigos encontrados e utilizados na pesquisa.

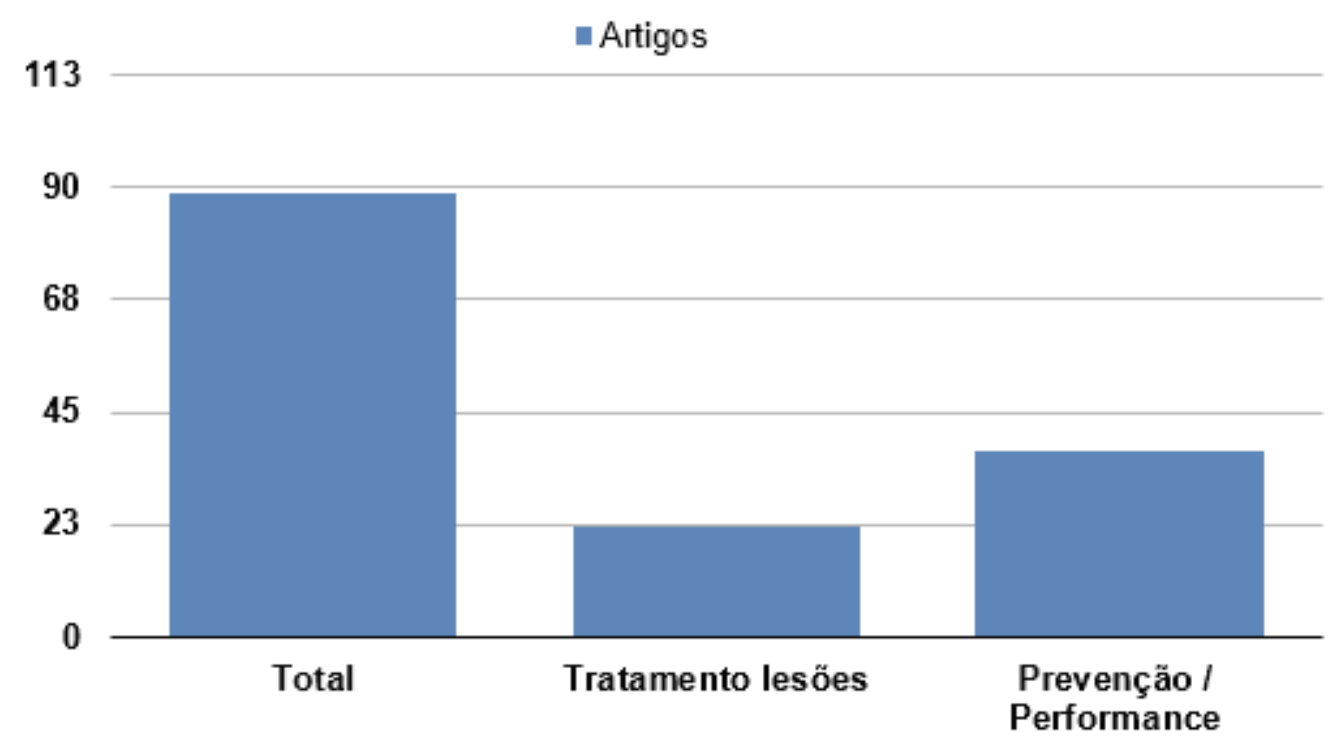


Tabela 1: Artigos relacionados com prevenção, melhora da performance atlética e tratamento de lesões esportivas.

\begin{tabular}{|c|c|c|}
\hline Autores & Título do Artigo & Periódicos/Anais/Congressos/Sites \\
\hline $\begin{array}{l}\text { Ehrlich D, Haber } \\
\text { P, } 1992\end{array}$ & $\begin{array}{l}\text { Influence of } \\
\text { acupuncture on pysical } \\
\text { performance capacity } \\
\text { and Haemodynamic } \\
\text { Parameters }\end{array}$ & J. Sports Med \\
\hline $\begin{array}{lr}\text { Santos } & \text { VC, } \\
\text { Kawano } & \text { MM, } \\
\text { Banja RA, } 2008\end{array}$ & $\begin{array}{l}\text { Acupuntura na melhora } \\
\text { da performance em } \\
\text { atletas juvenis de } \\
\text { handebol }\end{array}$ & Rev Saúde e Pesq \\
\hline $\begin{array}{l}\text { Rubio K, Godoy } \\
\text { Moreira F, } 2008\end{array}$ & $\begin{array}{l}\text { A dor em corredores } \\
\text { com fascite plantar: o } \\
\text { uso da acupuntura }\end{array}$ & Rev Dor \\
\hline $\begin{array}{ll}\text { Pires } & \text { TF, } \\
\text { Pellegrinotti } & \text { IL, } \\
2010 & \end{array}$ & $\begin{array}{l}\text { Acupuntura na } \\
\text { Performance Atlética: } \\
\text { Estudo Exploratório }\end{array}$ & 8 ${ }^{\text {M }}$ Mstra Acadêmica da UNIMEP \\
\hline $\begin{array}{l}\text { Yang HY, Liu TY, } \\
\text { Gao M, } 2006\end{array}$ & $\begin{array}{l}\text { Electrical acupoint } \\
\text { stimulation increases } \\
\text { athletes rapid strength }\end{array}$ & Zhongguo Zhen Jiu \\
\hline $\begin{array}{ll}\text { Luna } & \text { MP, } \\
\text { Fernandes } & \text { Filho } \\
\text { J, } 2005 & \end{array}$ & $\begin{array}{l}\text { Efeitos da Acupuntura } \\
\text { na performance de } \\
\text { Atletas velocista de alto } \\
\text { rendimento do Rio de } \\
\text { Janeiro }\end{array}$ & Fit e Perform J \\
\hline $\begin{array}{l}\text { Dias Junior JC, } \\
\text { Marino DM, } 2019\end{array}$ & $\begin{array}{l}\text { Acupuntura na } \\
\text { prevenção de lesões } \\
\text { musculares em atletas } \\
\text { de futebol profissional }\end{array}$ & Rev Fisiot S Fun \\
\hline
\end{tabular}




\begin{tabular}{|c|c|c|}
\hline Maciocia G, 2007 & $\begin{array}{l}\text { Os fundamentos da } \\
\text { medicina chinesa: um } \\
\text { texto abrangente para } \\
\text { acupunturistas } \\
\text { fitoterapeutas }\end{array}$ & Livro \\
\hline $\begin{array}{ll}\text { Akimoto } & \text { T, } \\
\text { Nakahori } & \text { C, } \\
\text { Aizawa } & \text { K, } \\
\text { Kimura } & \text { F, } \\
\text { Fukubayashi } & \text { T, } \\
\text { Kono I, 2003 } & \end{array}$ & $\begin{array}{l}\text { Acupuncture and } \\
\text { responses of imunoligic } \\
\text { and endocrine markers } \\
\text { during competition }\end{array}$ & Med Sci in Sports Exerc \\
\hline $\begin{array}{l}\text { Karvelas BR, } \\
\text { Hoffman MD, } \\
\text { Zeni Al, } 1996\end{array}$ & $\begin{array}{l}\text { Acute Effects of } \\
\text { Acupuncture on } \\
\text { Physiological and } \\
\text { Psychological } \\
\text { Responses to Cycle } \\
\text { Ergometry }\end{array}$ & Arch Phys Med Rehabil \\
\hline $\begin{array}{l}\text { Fry AC, Kraemer } \\
\text { KJ, } 1997\end{array}$ & $\begin{array}{l}\text { Resistance exercise ov } \\
\text { ertraing } \\
\text { and overreaching: neur } \\
\text { oendocrine responses }\end{array}$ & Sports Med \\
\hline KnardahI S, 1998 & $\begin{array}{l}\text { Sympathetic } \\
\text { nerve activity after } \\
\text { acupuncture in humans }\end{array}$ & $\begin{array}{l}\text { Department of } \\
\text { Neurophysiology }\end{array}$ \\
\hline $\begin{array}{l}\text { Barlas PJ, } \\
\text { Robinson JA, Ba } \\
\text { xter GD, } 2000\end{array}$ & $\begin{array}{l}\text { Lack ofeffect of acupun } \\
\text { cture upon signs } \\
\text { and symptoms of delay } \\
\text { ed } \\
\text { onset muscle soreness }\end{array}$ & Clinical Physio \\
\hline $\begin{array}{l}\text { Rossetto SC, } \\
2009\end{array}$ & $\begin{array}{l}\text { Acupuntura nos } \\
\text { Esportes }\end{array}$ & Livro \\
\hline
\end{tabular}




\begin{tabular}{|c|c|c|}
\hline $\begin{array}{l}\text { França D, } \\
\text { Fernandes- } \\
\text { Senna V, Cortez } \\
\text { CM, } 2004\end{array}$ & 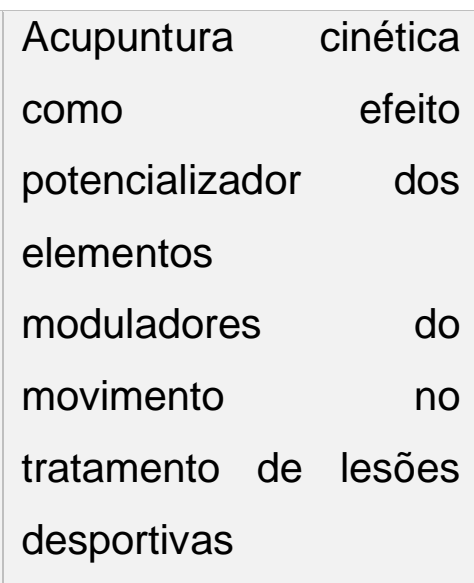 & Fisioter Bras \\
\hline $\begin{array}{l}\text { Wadsworth L T, } \\
2006\end{array}$ & $\begin{array}{l}\text { Acupuncture in sports } \\
\text { medicine }\end{array}$ & Curr Sports Med Rep \\
\hline Barela J A, 2000 & $\begin{array}{l}\text { Estratégias de Controle } \\
\text { em Movimentos } \\
\text { Complexos: Ciclo } \\
\text { Percepção - Ação no } \\
\text { Controle Postural }\end{array}$ & Rev Paul de Educ Fís \\
\hline $\begin{array}{l}\text { Papler PG et al., } \\
1999\end{array}$ & $\begin{array}{l}\text { Reabilitação do joelho. } \\
\text { In: Greve J.M. A. e } \\
\text { Amattuzzi, } \\
\text { Medicina M.M. } \\
\text { reabilitação aplicada à } \\
\text { ortopedia } \\
\text { traumatologia }\end{array}$ & Livro \\
\hline $\begin{array}{l}\text { Gemeo LH. } \\
\text { Ignatti C, } 2004\end{array}$ & $\begin{array}{l}\text { Acupuntura como } \\
\text { Ferramenta Auxiliar do } \\
\text { Aumento da } \\
\text { Performance } \\
\text { Desportiva. In: Anais do } \\
\text { Simpósio Internacional } \\
\text { de Ciências Integradas } \\
\text { da UNAERP }\end{array}$ & Anais Simpósio \\
\hline
\end{tabular}




\begin{tabular}{|c|c|c|}
\hline Frasca L, 2011 & $\begin{array}{l}\text { Desempenho na Ponta } \\
\text { da Agulha }\end{array}$ & Rev Farmac \\
\hline Costa V, 2013 & $\begin{array}{lr}\text { Acupuntura } & \text { Previne } \\
\text { Lesões e ajuda a } & \\
\text { melhorar } & \text { o } \\
\text { Desempenho } & \text { nas } \\
\text { Pistas [periódico na } \\
\text { internet] }\end{array}$ & $\begin{array}{l}\text { http://blogs.oglobo.globo.com/pulso/ } \\
\text { post/acupuntura-previne-lesoes- } \\
\text { ajuda-melhorar-desempenho-nas- } \\
\text { pistas-500798.html. }\end{array}$ \\
\hline Luna M, 2016 & $\begin{array}{l}\text { Os Benefícios da } \\
\text { Acupuntura no Esporte }\end{array}$ & $\begin{array}{l}\text { http://www.ibramrp.com.br/noticia/49 } \\
\text { /os-beneficios-da-acupuntura-no- } \\
\text { esporte }\end{array}$ \\
\hline $\begin{array}{l}\text { Bopp-Limoge C, } \\
1998\end{array}$ & $\begin{array}{l}\text { L’acupuncture Permet- } \\
\text { elle D`ameliorer les } \\
\text { Performances } \\
\text { Sportives Stude } \\
\text { Personnelle a Propos } \\
\text { de } 35 \text { Sportifs de haut } \\
\text { niveau. }\end{array}$ & These Medicine \\
\hline Lin ZP et al., 2009 & $\begin{array}{l}\text { Effects of acupuncture } \\
\text { stimulation on recovery } \\
\text { ability for male elite } \\
\text { basketball athletes }\end{array}$ & Amer Jour of Chin Med \\
\hline $\begin{array}{l}\text { Lin, ZP et al., } \\
2009\end{array}$ & $\begin{array}{l}\text { Effect of auricular } \\
\text { acupuncture on oxygen } \\
\text { consumption of boxing } \\
\text { athletes }\end{array}$ & Chin Med Jour \\
\hline $\begin{array}{l}\text { Dhillon S et al., } \\
2008\end{array}$ & $\begin{array}{l}\text { The acute effect of } \\
\text { acupuncture on } 20-\mathrm{km} \\
\text { cycling performance. }\end{array}$ & Clin Jour of Spo Med \\
\hline $\begin{array}{l}\text { Hubscher M et } \\
\text { al., } 2010\end{array}$ & $\begin{array}{l}\text { Immediate effects of } \\
\text { acupuncture }\end{array}$ & Euro Jour of Appli Physi \\
\hline
\end{tabular}




\begin{tabular}{|c|c|c|}
\hline & $\begin{array}{l}\text { strength performance: a } \\
\text { ramdomized, controlled } \\
\text { crossover trial }\end{array}$ & \\
\hline $\begin{array}{l}\text { Geng } L \text { J et al., } \\
1995\end{array}$ & $\begin{array}{l}\text { Investigation on the } \\
\text { effects of ear } \\
\text { acupressure on } \\
\text { exercise-induced lactic } \\
\text { acid levels and the } \\
\text { implications for athletic } \\
\text { training }\end{array}$ & Amer Jour of Acupu \\
\hline Franco RS, 2012 & $\begin{array}{l}\text { Avaliação do Efeito da } \\
\text { Acupuntura sobre o } \\
\text { Desempenho Físico } \\
\text { pelo Teste do Banco de } \\
\text { Harvard }\end{array}$ & Dissertação \\
\hline $\begin{array}{l}\text { Fonseca LP, } \\
\text { Lessa JFM, } 2011\end{array}$ & $\begin{array}{l}\text { Efeito da Aplicação da } \\
\text { Acupuntura na } \\
\text { Resistência Muscular } \\
\text { Localizada de Membros } \\
\text { Superiores em } \\
\text { Praticantes de } \\
\text { Exercício Resistido. }\end{array}$ & Mobografia \\
\hline $\begin{array}{lr}\text { Belmiro } & \text { H, } \\
\text { Vicentini } & \text { D, } \\
\text { Camilotti } & \text { CM, } \\
2013 & \end{array}$ & $\begin{array}{l}\text { Efeitos da Acupuntura } \\
\text { no Desempenho Motor } \\
\text { de Atletas. }\end{array}$ & Rev Fac Educ Fis \\
\hline $\begin{array}{l}\text { Rubio K; Godoy } \\
\text { Moreira F, } 2007\end{array}$ & $\begin{array}{l}\text { A representação da dor } \\
\text { em atletas olímpicos } \\
\text { brasileiros }\end{array}$ & Rev Dor \\
\hline Parisotto D, 2014 & $\begin{array}{ll}\text { Efeito Imediato } & \mathrm{da} \\
\text { Aplicação } & \mathrm{da}\end{array}$ & Dissertação \\
\hline
\end{tabular}




\begin{tabular}{|c|c|c|}
\hline & $\begin{array}{l}\text { Acupuntura na Dor } \\
\text { Muscular Tardia e na } \\
\text { Capacidade de } \\
\text { Contração Muscular }\end{array}$ & \\
\hline Staud R, 2007 & $\begin{array}{l}\text { Mechanisms of } \\
\text { acupunture analgesia: } \\
\text { effective therapy for } \\
\text { musculoskeletal pain? }\end{array}$ & Curr rheumatol Rep \\
\hline $\begin{array}{l}\text { Bucinskaite V, } \\
\text { Lundeberg T, } \\
\text { Stenfors C, } \\
\text { Ekblom A, Dahlin } \\
\text { L, Theodorsson } \\
\text { E, } 1994\end{array}$ & $\begin{array}{l}\text { Effects of electro- } \\
\text { acupuncture and } \\
\text { pysical exercice on } \\
\text { regional concentrations } \\
\text { of neuropeptides in rat } \\
\text { brain }\end{array}$ & Brain research \\
\hline Shang C, 2009 & $\begin{array}{l}\text { Prospective tests on } \\
\text { biological models of } \\
\text { acupuncture }\end{array}$ & $\begin{array}{l}\text { Evid Based Complement Alternat } \\
\text { Med. }\end{array}$ \\
\hline Bowsher D,1988 & $\begin{array}{l}\text { Mechanisms of } \\
\text { acupuncture. In: Filshie } \\
\mathrm{J} \text {, White A. editors. } \\
\text { Medial Acupuncture: a } \\
\text { western scientific } \\
\text { approach. }\end{array}$ & Livro \\
\hline Ma SX, 2004 & $\begin{array}{l}\text { Neurobiology } \\
\text { acupuncture: } \\
\text { CAM }\end{array}$ & $\begin{array}{l}\text { Evid Based Complement Alternat } \\
\text { Med }\end{array}$ \\
\hline $\begin{array}{l}\text { Li J, Wang Q, } \\
\text { Liang H, Dong H, } \\
\text { Li Y, Ng EH, et al., } \\
2012\end{array}$ & $\begin{array}{l}\text { Biophysical } \\
\text { characteristics of } \\
\text { meridians and } \\
\text { acupoints: a systematic } \\
\text { review. }\end{array}$ & $\begin{array}{l}\text { Evid Based Complement Alternat } \\
\text { Med. }\end{array}$ \\
\hline
\end{tabular}


Lee, SH, Chung, Effects Acupunturaq on Neurocienses Letters

SH, Lee, JS, Kim, the 5-

SS, Shin, HD, hydroxytryptamine

Lim, BV, et al., synthesis and

2002 tryptophan hydroxylase

expression in dorsal in

the dorsal raphe of

exercice rats.

Zyloney CE, Imaging the functional Mol pain

Jensen K, Polich connectivity of the

G, Loiotile RE, Periaqueductal Gray

Cheetham A, during genuine and

LaViolette PS, et sham

al., 2010 electroacupuncture treatment.

Minori AET, Mejia Atuação da Acupuntura Monografia

DPM, 2007 para o Tratamento de LER/DORT no Ombro.

$\begin{array}{lrlr}\text { Brum KN, } & \text { Tratamento } & \text { de } \\ \text { Alonso, AC, } & \text { massagem } & \text { e } \\ \text { Brech GC, 2009 } & \text { acupuntura } & \text { em } \\ & \text { corredoresrecreacionai } \\ & \text { s com síndrome do } \\ & \text { piriforme }\end{array}$

Hongwen S, 2003 Clinical Observation on J Tradit Chin Med.

Acupuncture Treatment of Piriformis Syndrome.

Rocha TBX, Análise Comparativa Rev Bras Cien e Mov

Vilela Junior GB, Eletromiográfica do

Martins GC, Reto Femoral em

Isometria na Posição 


\begin{tabular}{|c|c|c|}
\hline $\begin{array}{l}\text { Manzatto L, } \\
\text { Grande AJ, } 2012\end{array}$ & $\begin{array}{lr}\text { Inferior } & \text { do } \\
\text { Agachamento } & \text { Wall } \\
\text { Slide, antes e após a } \\
\text { Aplicação } & \text { da } \\
\text { Acupuntura no } & \text { Ponto } \\
\text { ST45 }\end{array}$ & \\
\hline $\begin{array}{l}\text { Pinheiro RG, } \\
\text { Mejia DPM, } 2012\end{array}$ & $\begin{array}{l}\text { Efeito da Acupuntura na } \\
\text { Melhora do Paciente } \\
\text { com Quadro Álgico de } \\
\text { Lesão de Menisco } \\
\text { Medial. }\end{array}$ & Monografia \\
\hline $\begin{array}{l}\text { Nunes EA, Mejia } \\
\text { DPM, } 2012\end{array}$ & $\begin{array}{lr}\text { Tratamento } & \text { de } \\
\text { Acupuntura } & \text { para } \\
\text { Combater Dores nos } \\
\text { Ombros. }\end{array}$ & Monografia \\
\hline Tolentino F, 2016 & $\begin{array}{l}\text { Efeito de um } \\
\text { Tratamento com } \\
\text { Auriculoterapia na Dor, } \\
\text { Funcionalidade } \\
\text { Mobilidade de Adultos } \\
\text { com Dor Lombar } \\
\text { Crônica. }\end{array}$ & Dissertação \\
\hline
\end{tabular}

\section{ACUPUNTURA NA PREVENÇÃO DE LESÕES}

A prevenção de lesões no esporte é uma grande batalha a ser vencida pelos profissionais que trabalham com atletas. No futebol a lesão muscular corresponde a $20-40 \%$ de todas as lesões esportivas, predominando de $80-90 \%$ nos membros inferiores. ${ }^{15}$

A lesão muscular é a grande vilã de todos os atletas, de vários esportes, podendo deixá-los afastados das suas atividades por um longo período. Sendo assim, torna-se 
interessante a apresentação uma proposta de intervenção profilática, trazendo a ideia de uma técnica para prevenir ou diminuir os riscos deste tipo de lesão em atletas. Neste caso a acupuntura mostra ser uma técnica benéfica.

Em seu estudo, Dias Junior ${ }^{16}$, contou com a presença de 54 atletas, do sexo masculino, pertencentes a uma equipe de futebol profissional. Foram distribuídos em 6 grupos: grupo 1 - acupuntura para reequilibrar o sistema, encontrado através da avaliação; grupo 2 - que recebeu protocolo com pontos específicos: baço pâncreas 3 , baço pâncreas 6 (Figura 1A) e estômago 36 (Figura 1B); grupo 3 - estômago 36 (Figura 1B); grupo 4 - baço pâncreas 6 (Figura 1A); grupo 5 - acupuntura auricular; grupo controle - não recebeu nenhuma intervenção. Após oito sessões, sendo uma por semana, os resultados mostraram: grupos 1 e 2 não apresentaram nenhum tipo de lesão; grupo 4: duas lesões; grupos 3 e 5: apresentaram 1 lesão; controle: apresentou 6 casos de problemas musculares. 
Figura 1 A: baço pâncreas 3 - no lado medial do pé, póstero-inferior da articulação metatarso-falangeana, na linha da junção da pele escura e clara; baço pâncreas 6: 3 tsun acima do maléolo medial, na borda póstero-medial da tíbia; B: estômago 36 - 3 tsun abaixo da patela entre o músculo da tíbia anterior e o músculo extensor longo dos dedos; estômago 37 - 3 tsun abaixo de Zusanli (E36), no lado anterior lateral do músculo da tíbia; estômago 38 - 8 tsun abaixo do joelho, 2 tsun abaixo do ponto Shangjuxu (E37), no lado do músculo anterior da tíbia; estômago 41 - no ponto médio dorsal do tornozelo acima do ligamento cruciato, entre os tendões do músculo extensor hallux longo e o extensor longo dos dedos.

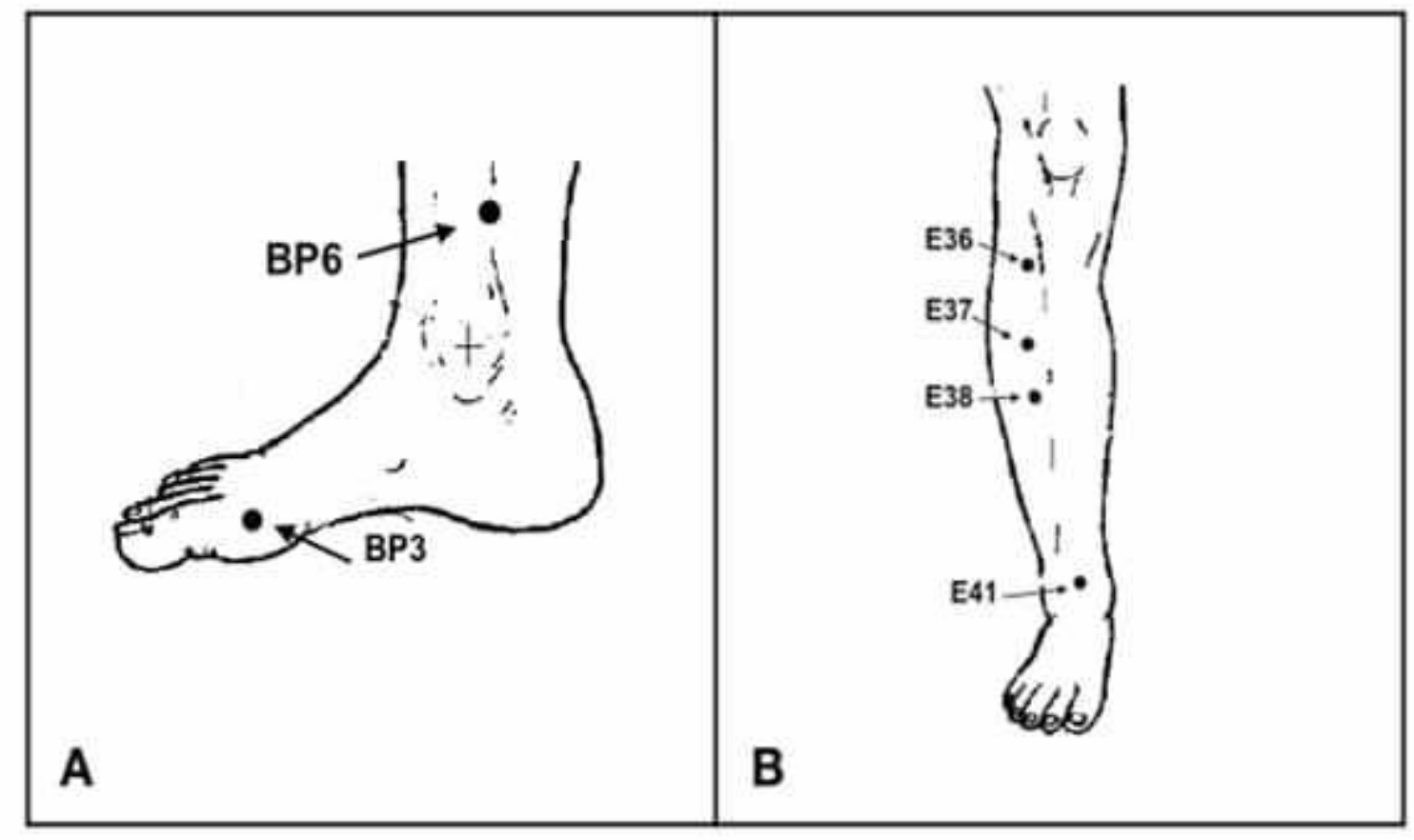

Fonte: Wen ${ }^{17}$

O baço pâncreas tem a função de extrair a energia dos alimentos, distribuir para o corpo e controlar o sangue dentro dos vasos sanguíneos. O Qi se apresentando forte será transportado para todos os músculos do corpo, especificamente para os membros, mas se o Qi estiver em deficiência, a energia não será transmitida para o tecido muscular e o atleta apresentará fadiga e os músculo enfraquecido. ${ }^{18}$

Segundo Ross ${ }^{19}$, os pontos baço pâncreas 3 e 6 são associados com o estômago 36 tonificando $\circ$ Qi do sangue. O elemento terra é o responsável pelo equilíbrio 
energético e pela disponibilização do Qi e sangue como fontes de energia para atividade mentais, emocionais e físicas. A MTC, relata que ao tonificar este elemento, mantem os músculos nutridos por Qi e Xue (sangue na MTC), objetivando a melhora do desempenho atlético. Isto mantém a obrigatoriedade de tonificar o órgão que produz Xue (Fígado) e mantém o fluído energético (Baço Pâncreas e Rim), já que a funcionalidade do sangue é nutrir o corpo, além de completar a ação de nutriente do Qi.

A capacitação muscular, relaxamento e força contrátil, está relacionado com a nutrição de xue do fígado. Se a nutrição estiver deficitária ocorrerá câimbras e parestesia dos membros ocasionando lesões. Por outro lado baço monitora o xue dentro dos vasos e retira o Qi dos alimentos transmitindo para o organismo: Qi forte, transmitirá uma boa energia para os músculos; um Qi debilitado, resultará num músculo cansado e fraco. ${ }^{19,20}$

Com base nessas evidências esta técnica é praticada nos esportes apresentando resultados rápidos, melhorando a qualidade da força muscular, condições cardiorrespiratórias, flexibilidade e bem estar mental e físico de esportistas. ${ }^{20,21,22}$ Yang e colaboradores ${ }^{22}$, atingiu aumento significativo da força muscular, proporcionando melhora da velocidade dos atletas. Por sua vez, Luna e colaboradores 24, afirmaram que a estimulação de pontos de acupuntura melhoram a performance esportiva, a plasticidade muscular prevenindo lesões.

Um estudo realizado no Japão ressalta o efeito da acupuntura no bem estar físico de jogadoras de futebol feminino durante a competição. Elas foram divididas em dois grupos, onde um foi submetido ao tratamento e o outro controle. Foram avaliados através da secreção SlgA (avalia sistema imunológico), níveis de cortisol (avalia sistema endócrino) e avaliação do bem estar físico através do questionário POMS (avalia o estado físico e mental): foi observado uma melhora no sistema imune (diminuição da secreção SlgA), melhora do estresse mental (diminuição de cortisol) e melhora no bem estar físico, flexibilidade e na tensão muscular. ${ }^{25}$ 
Contudo Ehrlich e colaboradores ${ }^{25}$, conquistou uma melhora do desempenho atlético, aumentando o nível do bem estar físico, melhorando a resposta competitiva, durante treinamentos e jogos, auxiliando na recuperação da capacidade muscular.

Outras lesões que podem ser prevenidas com acupuntura são os entorses de tornozelo, que acometem os ligamentos, desencadeando muitas dores e limitação da função articular. França ${ }^{26}$, utilizou os pontos ashi (pontos dolorosos a palpação), associados com bexiga 60 (Figura 2A) para eliminar a dor; o vesícula biliar 39 que reforça os ossos, tendões e combate a algia nas extremidades; e vesícula biliar 40 estimula o Qi e xue; estômago 41 (Figura 2B) que trata as alterações laterais do tornozelo e o estômago 36 (Figura 1B) eliminando a obstrução e estimulando a circulação de Qi e xue local.

Figura 2 A: bexiga 60 - entre o tendão de Aquiles e a borda do maléolo lateral do tornozelo, ao nível do ponto mais alto do maléolo; B: vesícula biliar 39 - 3 tsun acima do ponto mais alto do maléolo externo, na depressão entre a fíbula e os tendões fibulares longo e curto e vesícula biliar 40 - no lado ântero-inferior do maléolo externo, na depressão lateral do tendão do músculo extensor digital longo; estômago 41 - no ponto médio dorsal do tornozelo acima do ligamento cruciato, entre os tendões do músculo extensor halux longo e o extensor longo dos dedos.

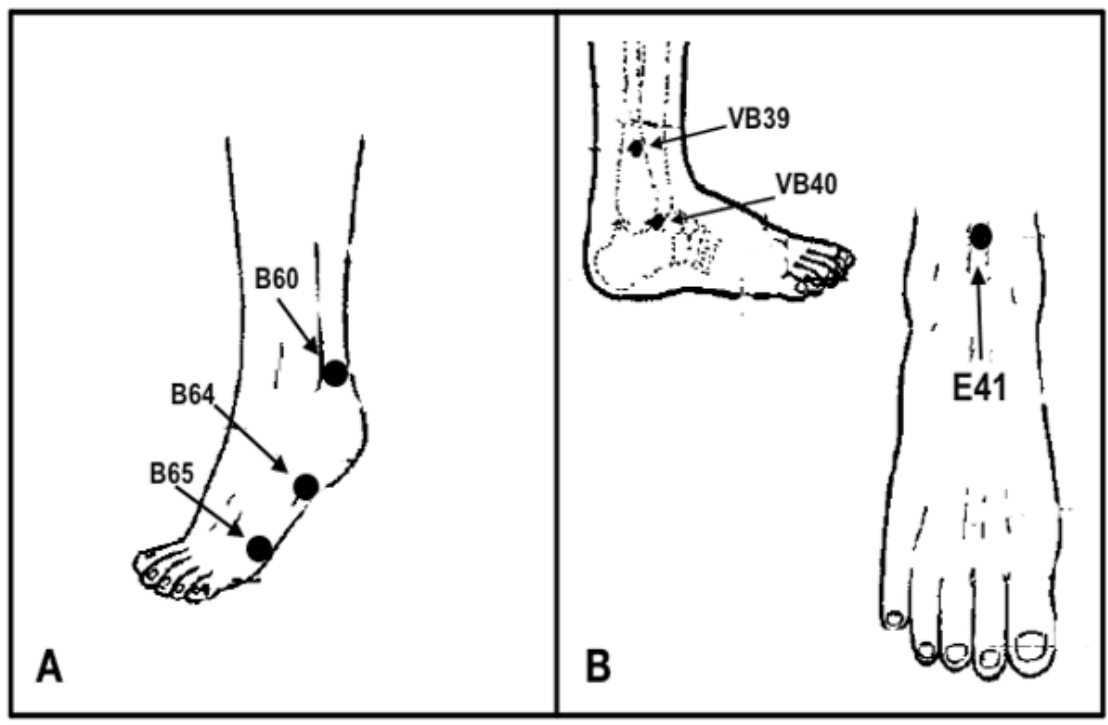

Fonte: Wen ${ }^{17}$ 
Alguns atletas podem ser surpreendidos com torcicolor, que é definida como uma lesão tendinosa cervical que causa dor e rigidez muscular. Existe um protocolo para sanar este problema e devolver o atleta as suas funções. Wadsworth ${ }^{27}$, utilizou além dos pontos ashi que estimulam a circulação do Qi e xue, o vesícula biliar 39 (Figura 2B), vesícula biliar 20 atua na circulação do Qi e xue, relaxando os tendões e amenizam as dores; vaso governador 14 expulsando o fator patogênico e regulando o Qi do meridiano; o bexiga 10; intestino delgado 14; vesícula biliar 21 (Figura 3A) estimulam a circulação do Qi e do xue. Se o bloqueio articular limitar a flexão e extensão, usar o ponto bexiga 60 (Figura 2A). Os pontos intestino delgado 3 , o pulmão 7 promovem a circulação do Qi e xue do pescoço, caso apresente limitação de rotação, usar o ponto intestino delgado 7 que drena o meridiano Taiyang da mão (Figura 3B). 
Figura 3 A: vesícula biliar 20 - abaixo da borda occipital na depressão entre os músculos trapézio e esterno-clidomastóideo, na margem do cabelo e vesícula biliar 21 - no ponto eqüidistante entre o Dazhui (VC14) e o acrômio do ombro, 1 tsun acima do ponto Tianliao; vaso governador 14 - no ponto médio entre os processos espinhosos; sétima vértebra cervical e primeira vértebra dorsal; bexiga 10 - no nível entre as espinhas da segunda e terceira vértebras, 1,3 tsun lateral da linha média dorsal, no lado da borda do músculo trapézio e intestino delgado 14 - 3 tsun laterais da linha central da vértebra; no nível horizontal da borda inferior do processo espinhoso da primeira vértebra dorsal; B: pulmão 7 - no lado medial do antebraço, 1,5 tsun acima da linha do punho entre os tendões do músculo adutor longo do polegar e do músculo extensor longo carpo-radial; intestino delgado 3 - lado ulnar da mão, atrás da junta metacarpo-falangiana do quinto dedo, entre as peles clara e escura; intestino delgado 7 - 5 tsun acima do punho, no lado ulnar do músculo extensor carpo-ulnar.

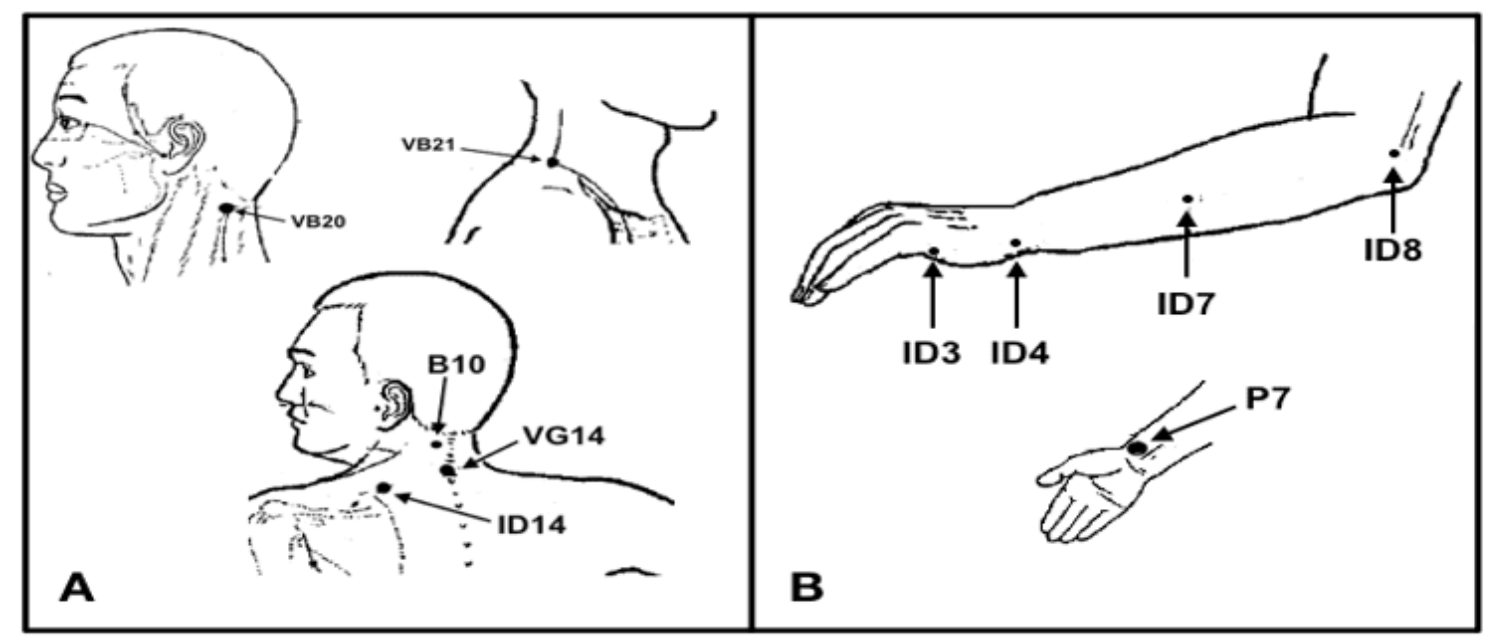

Fonte: Wen ${ }^{17}$

A sobrecarga na articulação do cotovelo, acomete, principalmente tenistas, podendo levar a um bloqueio do Qi e xue, desencadeando uma inflamação crônica denominada epicondilite. Os pontos ashi são utilizados na região promovendo a estimulação do Qi. 28

Para tratamento de lesões no punho, como: tendinites ou tenossinovites do polegar, extensores e flexores dos dedos, França ${ }^{26}$, utilizou os ponto ashi associados com 
intestino grosso 5 para dispersar o calor do meridiano; intestino delgado 5 eliminando o calor e desbloqueando o punho (Figura 4A); triplo aquecedor 4 que além de eliminar o calor cessa a inflamação e o intestino grosso 11 (Figura 4B) desbloqueando o Qi e o xue acalmando a dor.

Figura 4 A: intestino delgado 5 - no lado ulnar do punho, na depressão entre o pisiforme e o processo estilóide ulnar; intestino grosso 5 - no lado dorso-radial do punho, um pouco distal do osso rádio, onde há depressão entre os tendões do músculo extensor curto e longo do polegar, ao esticar e abrir o polegar. B: triplo aquecedor 4 - no lado dorsal do punho, na depressão no meio da dobra dorsal do punho, entre os tendões dos músculos extensor digital comum e extensor digital do quinto dedo;intestino grosso 11 - no lado radial do cotovelo, no músculo braquiorradial; ao dobrar o cotovelo, na depressão radial no fim da linha cubital.

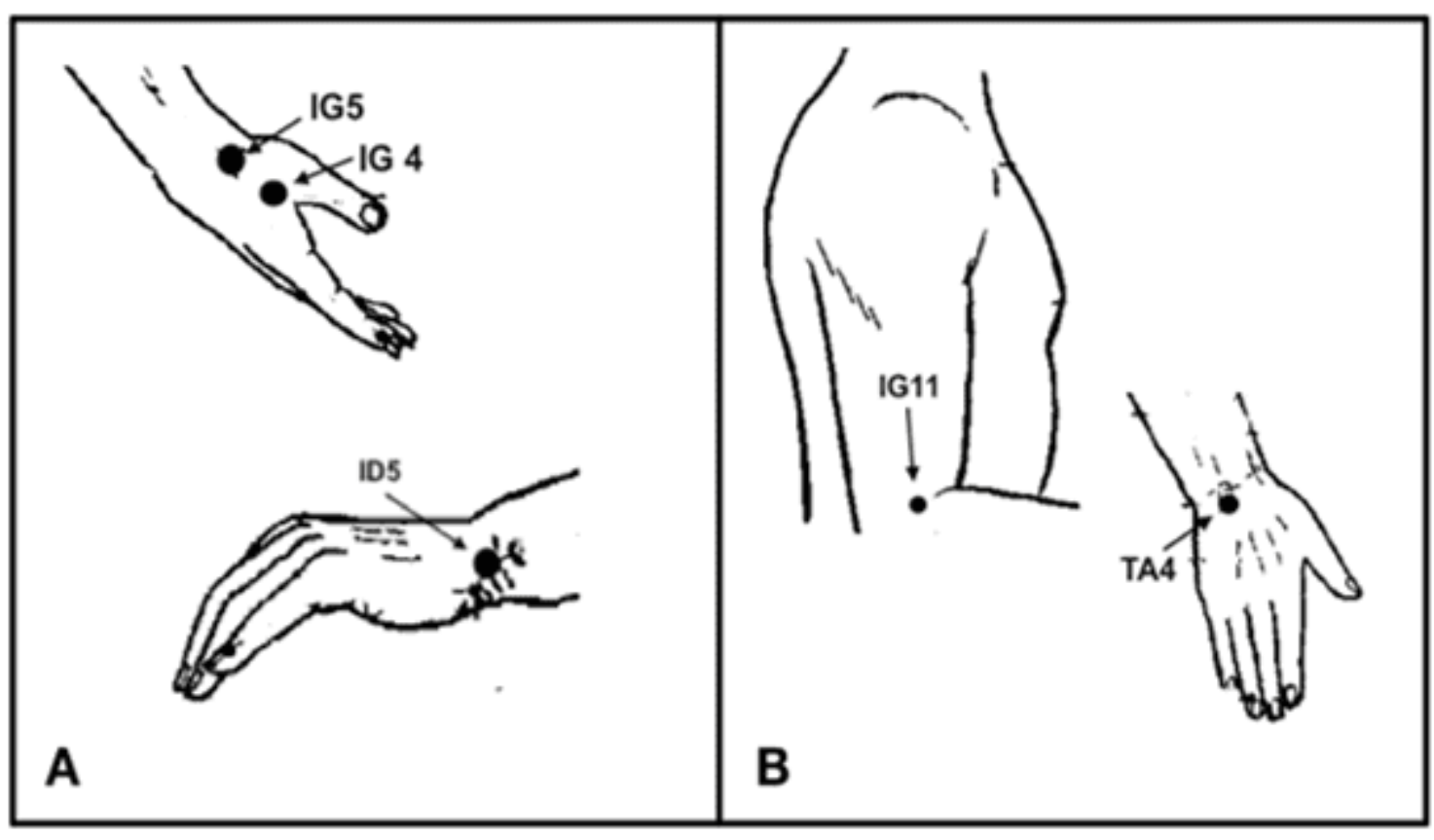

Fonte: Wen ${ }^{17}$

Já para nos quadros de lombalgias, Barela ${ }^{17}$, associou os pontos ashi com bexiga 23 e bexiga 25 para estimular o Qi e Xue local, bexiga 40 (Figura 5) que elimina a dor e o calor. 
Figura 5: bexiga 23 - 1,5 tsun, lateral da borda inferior do processo espinhal da vértebra (L2); bexiga 25 - 1,5 tsun, lateral da borda inferior do processo espinhal da vértebra (L4); bexiga 40 - 3 tsun, lateral da linha central (Du-Mai), no nível da borda inferior na segunda espinha da vértebra (T2).

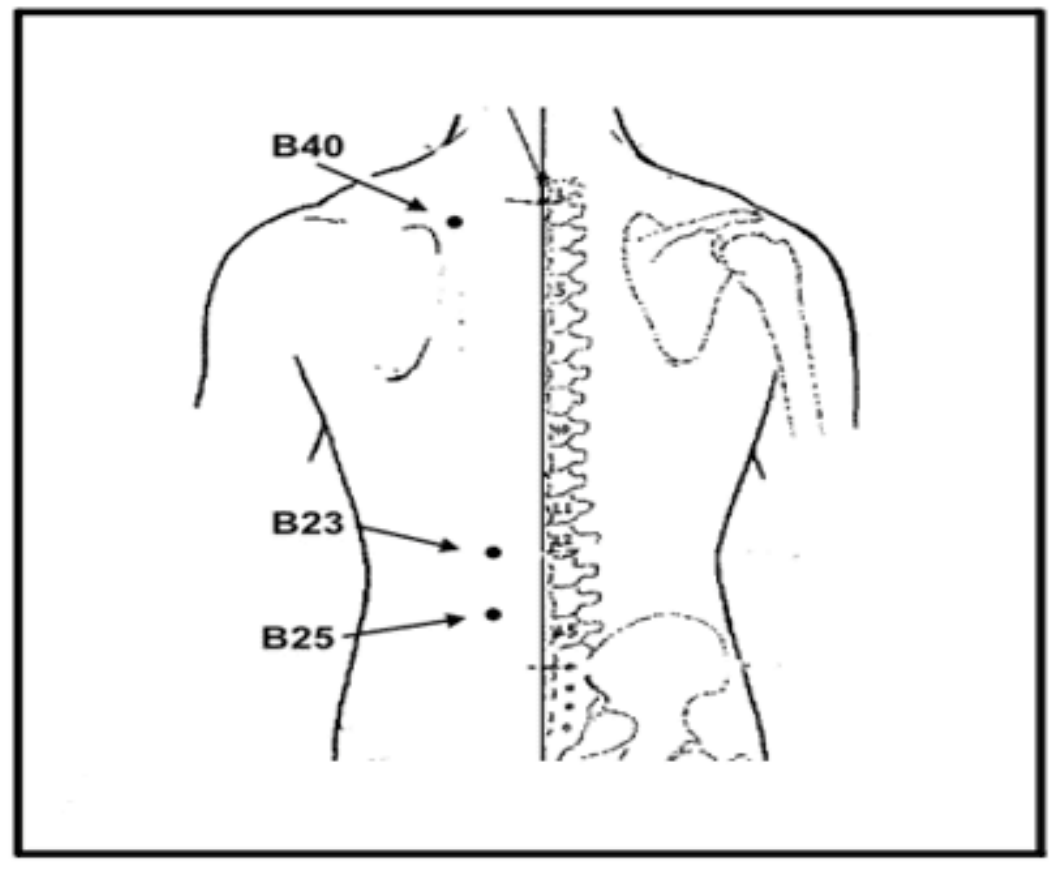

Fonte: Wen ${ }^{17}$

Agora outra lesão que preocupa atletas de futebol, são as ligamentares, meniscais e tendíneas do joelho. Esta são tratadas com os pontos ashi, associados com vesícula biliar 33 (Figura 6) que relaxa os tendões e trata da dor; bexiga 40 (Figura 5) elimina a dor, edema e o calor da articulação, estimulando Qi e xue; estômago 36 (Figura 1B) que regulando o fluxo de Qi e xue do meridiano eliminando a obstrução. ${ }^{29}$ 
Figura 6: vesícula biliar 33 - na borda lateral do joelho, 3 tsun acima do ponto Yanglingquan (VB34), na depressão superior do epicôndilo lateral do fêmur.

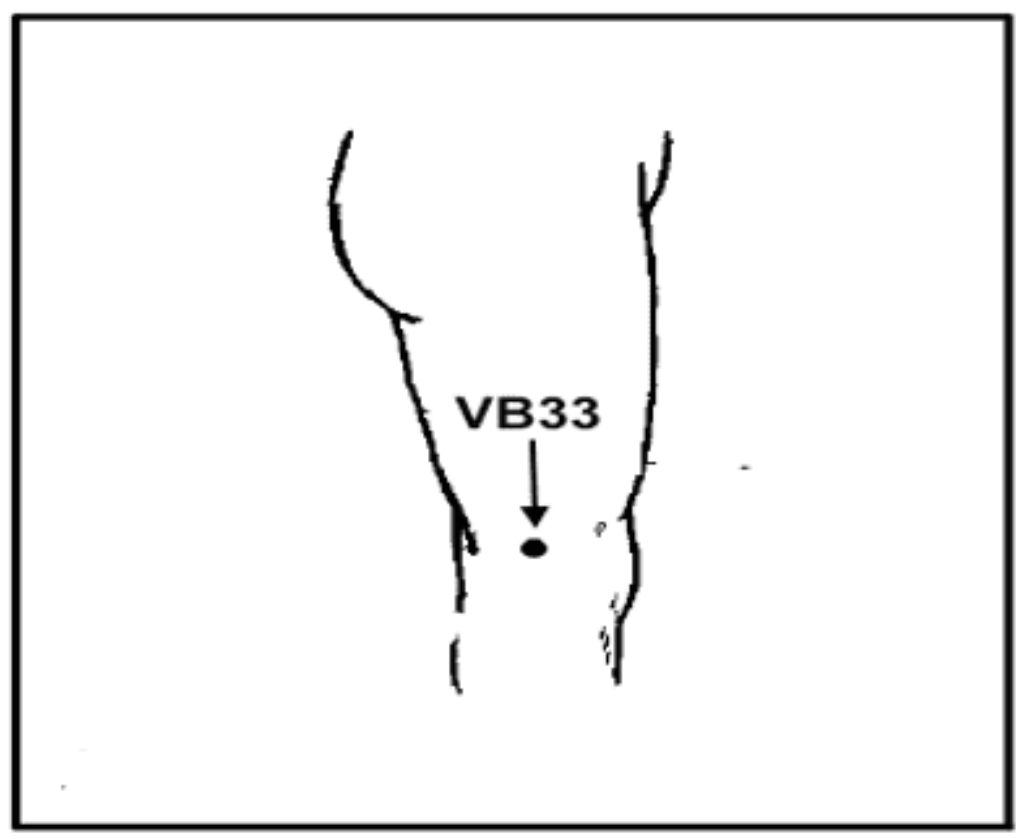

Fonte: Wen ${ }^{17}$

Gemeo ${ }^{30}$, firmou que a acupuntura pode promover uma melhora da capacidade física de atletas, prevenir e tratar lesões que possam ocorrer antes, durante ou depois das competições esportivas, além de auxiliar e influenciar os fatores emocionais como ansiedade, irritabilidade, insônia e depressão, que podem atrapalhar diretamente na capacidade atlética destes indivíduos. Ele desenvolveu um protocolo específico utilizando pontos mestres de acupuntura, selecionando de acordo com a modalidade (Quadro 1):

Tabela 2: Gemeo ${ }^{30}$

\begin{tabular}{|c|c|c|}
\hline $\begin{array}{l}\text { Mestre } \\
\text { moral }\end{array}$ & da energia & vaso governador 19 (Figura 7) \\
\hline $\begin{array}{l}\text { Mestre } \\
\text { geral }\end{array}$ & da energia & $\begin{array}{l}\text { influencia a energia geral, atuando na energia ancestral } \\
\text { e pós natal - vaso governador } 4,6,10,13 \text { (Figura } 7 \text { ) }\end{array}$ \\
\hline
\end{tabular}




\begin{tabular}{|c|c|}
\hline $\begin{array}{l}\text { Mestres dos membros } \\
\text { superiores }\end{array}$ & $\begin{array}{l}\text { atua nos movimentos do antebraço, punhos, mãos e } \\
\text { ombros: triplo aquecedor } 15 \text { (Figura } 7 \text { ) }\end{array}$ \\
\hline pulmões & interfere no tórax anterior: pulmão 1 (Figura 7) \\
\hline Mestre do dorso & $\begin{array}{l}\text { comanda diafragma, respiração e nn. frênico: bexiga17 } \\
\text { (Figura 7) }\end{array}$ \\
\hline Mestre do ventre & $\begin{array}{l}\text { influencia sobre a cintura abdominal: estômago } 27 \\
\text { (Figura } 7 \text { ) }\end{array}$ \\
\hline Mestre dos rins & atua a cintura lombar: bexiga 47 e bexiga 52 (Figura 8) \\
\hline Mestre do quadril & age os mm. glúteos e articulação coxofemoral (Figura 8) \\
\hline Mestre da coxa & $\begin{array}{l}\text { atua na musculatura das coxas: vesícula biliar } 30 \text { (Figura } \\
\text { 8) }\end{array}$ \\
\hline $\begin{array}{l}\text { Mestre dos membros } \\
\text { inferiores }\end{array}$ & $\begin{array}{l}\text { influencia a ação dos pés e músculos em geral: bexiga } \\
58 \text { (Figura 8) e estômago } 36 \text { (Figura 1B) }\end{array}$ \\
\hline $\begin{array}{l}\text { Pontos para melhora } \\
\text { do equilíbrio e reflexo }\end{array}$ & $\begin{array}{l}\text { vaso concepção 4, vaso concepção } 6 \text { (Figura 9), intestino } \\
\text { grosso } 11 \text { (Figura 4B), bexiga } 46 \text { (Figura 8), vaso } \\
\text { governador } 4 \text { (Figura } 7 \text { ). }\end{array}$ \\
\hline
\end{tabular}


Figura 7: vaso governador 4 - na linha central da espinha da coluna; no espaço entre as espinhas da segunda e terceira vértebras lombares; vaso governador 6 - na linha central da coluna; entre o décimo primeiro e o décimo segundo processo espinhoso das vértebras dorsais; vaso governador 10 - na linha central da coluna; entre o sexto e o sétimo processo espinhoso das vértebras dorsais; vaso governador 13 - na linha central da coluna; entre o primeiro e o segundo processo espinhoso das vértebras dorsais; vaso governador 19 - 1,5 tsun atrás do Baihui (VG 20); estômago 27 - 2 tsun abaixo do umbigo e 2 tsun ao lado da linha medial na borda lateral do músculo retoabdominal; bexiga 17 - 1,5 tsun da linha central, no nível da borda inferior do processo espinhal da vértebra (T7); pulmão 1 - no lado ântero-lateral do peito, abaixo do ponto Yunmen (P2) (fossa entre a clavícula e o ombro), no espaço entre a primeira e a segunda costela, 6 tsun do lado da linha média do corpo; triplo aquecedor 15 - na fossa supra-escapular, entre Quyuan (ID13) e Jianjing (VB21).

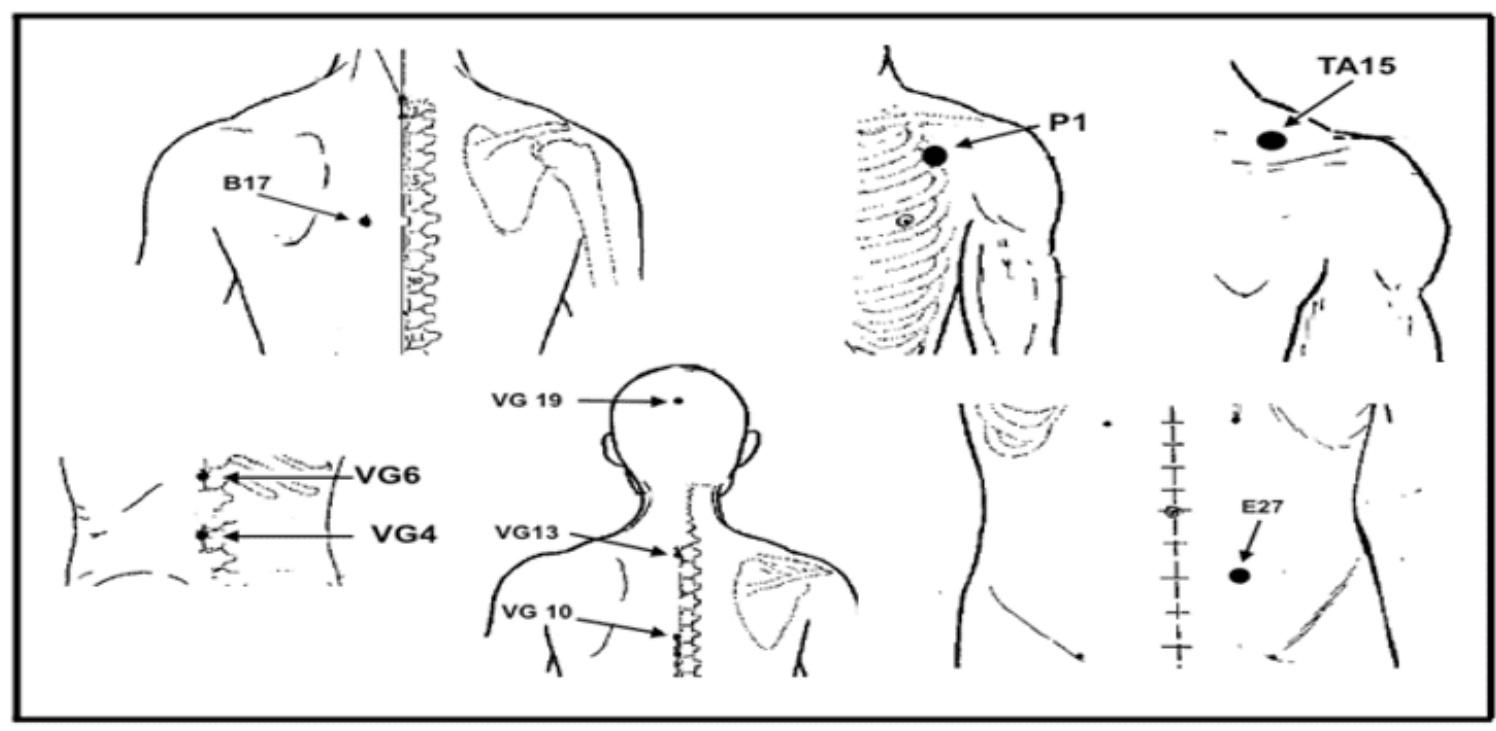

Fonte: Wen ${ }^{17}$

Figura 8: bexiga 46 - 3 tsun, lateral da linha central, no nível da borda inferior da espinha da vértebra (T9); bexiga 47 - 3 tsun, lateral da linha central, no nível da borda inferior da espinha da vértebra (T10); bexiga 52 - 3 tsun, lateral da linha central, no nível da segunda espinha do sacro, na borda lateral da junta iliossacral; bexiga 58 - I tsun abaixo do lado lateral do ponto Chengshan (B57); 7 tsun acima do calcanhar, no lado lateral do tendão do músculo gastrocnêmio; vesícula biliar 30 - na nádega, na 
linha entre o hiato da sacra e o proeminente do trocânter maior; um terço da distância lateral na borda inferior do músculo piriforme; ponto extra do quadril - no meio da linha que vai da extremidade superior do sulco interglúteo à parte da crista externa do ísquio.

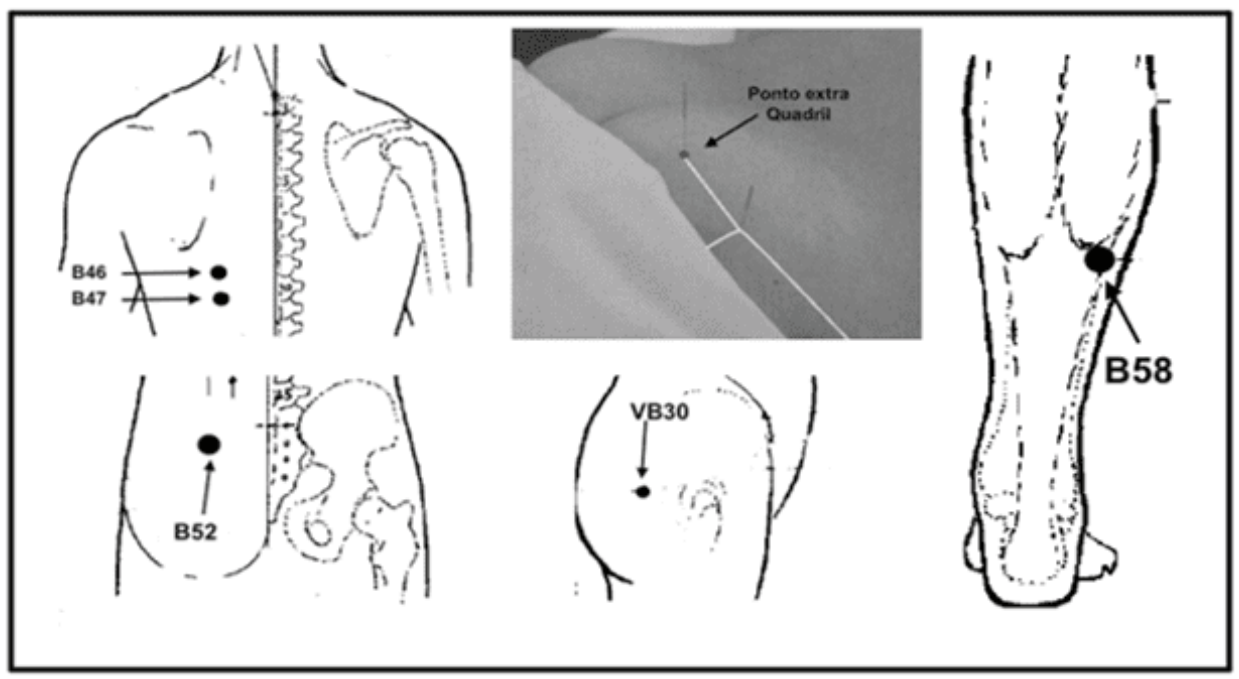

Fonte: Wen ${ }^{17}$; Rosseto ${ }^{31}$

Figura 9: vaso concepção 4 - 3 tsun abaixo do umbigo, na linha central do abdômen; vaso concepção 6 - 1,5 tsun abaixo do umbigo, na linha central do abdômen.

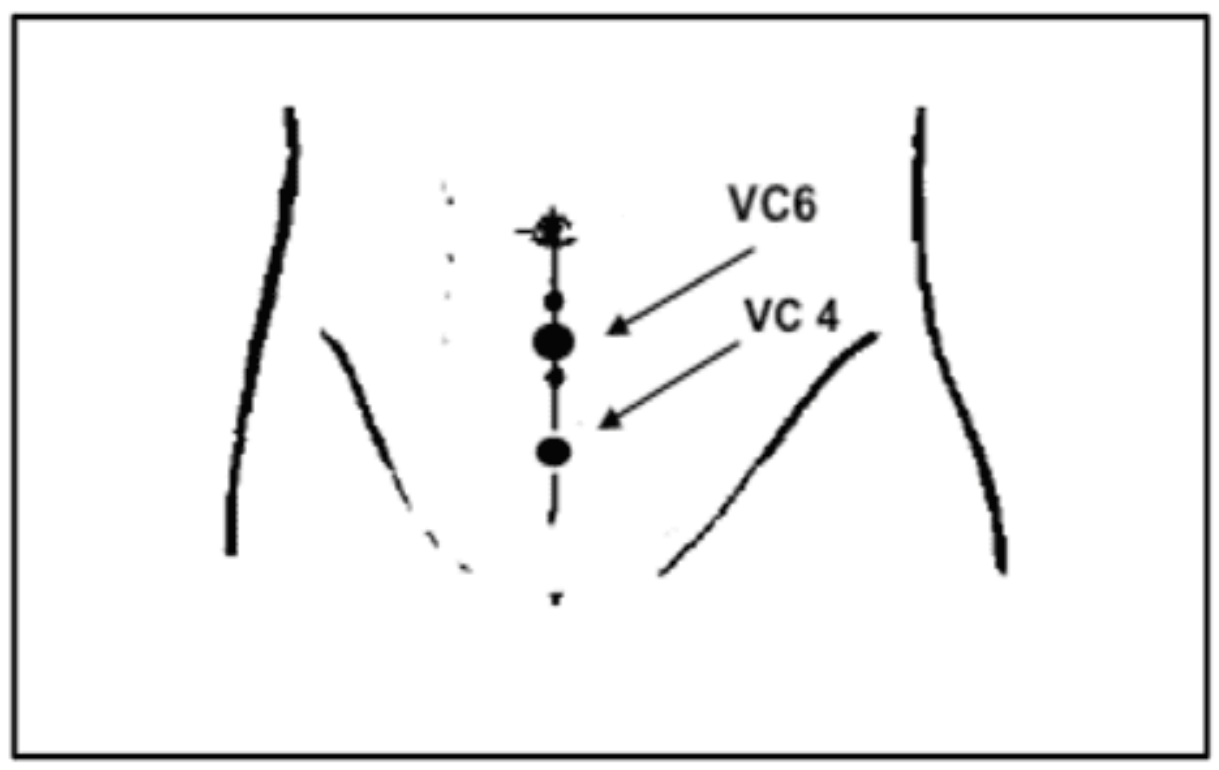

Fonte: Wen ${ }^{17}$ 


\section{ACUPUNTURA NA MELHORA DA PERFORMANCE ATLÉTICA}

Quando se tratamos de acupuntura na prevenção de lesões em atletas, não podemos esquecer que atingindo este objetivo preventivo, consequentemente melhoramos a qualidade e a integridade física podendo intervir na melhora da performance.

Em países da Ásia a utilização da acupuntura desenvolve um bem estar físico aos atletas, regulado pelos sistemas nervoso, endócrino, imune e em conseqüência disso, uma melhora da condição física em diversas modalidades. ${ }^{32,31,34}$ Além disso existem pontos aplicados antes, durante e depois dos treinamentos e jogos, que auxiliam na manutenção da musculatura, como na redução do ácido lático, diminuindo as dores, a fadiga, acelerando a recuperação e melhorando o desempenho. ${ }^{35}$

A acupuntura estimula a liberação de substâncias bioquímicas que alivia a fadiga muscular oriundos dos exercícios intensos, além de promover o aumento da atividade antioxidante, diminuindo os índices de estresse oxidativos. Durante um estudo os atletas receberam o tratamento com eletroacupuntura por 30 minutos, num período de 30 dias e o resultado foi o aumento de significativo de superóxido dismutase (SOD) e diminuição no malondialdído (MDA) sanguíneo. Superóxido dismutase é uma enzima com efeitos antioxidantes e que protege as células contra substâncias toxicas, exercendo potente resposta anti-inflamatória no organismo. O MDA está relacionado com doenças inflamatórias e degenerativas, permitindo aos pesquisadores concluírem que a eletroacupuntura diminui os índices de MDA e aumenta o SOD, contribuindo para o alívio da fadiga e melhorar a performance física. ${ }^{36}$

Embora seja uma técnica milenar, a sua utilização melhora do desempenho físico e mental do atleta é recente. Luna, publicou uma pesquisa demonstrando que acupuntura melhorava estatisticamente a força máxima e a potência de atletas velocistas (de 100, 200 e 400 metros rasos sem barreiras) e desde então as pesquisas nesse quesito, vem sendo aprofundadas. ${ }^{37}$

Em pesquisa, Santos ${ }^{20}$, utilizou atletas de Handbol do sexo masculino, entre 15 e 17 anos, onde realizou dois tiros de 100 metros em cada atleta (pré acupuntura). Após 
45 minutos da aplicação do protocolo escolhido para tratamento, reavaliou da mesma forma. Os pontos escolhidos foram: bexiga 58 (Figura 8) mestre das pernas e do pé; estômago 36 (Figura 1B) tonifica a musculatura estriada e é usado para potencializar o tratamento; ponto extra mestre dos quadris (Figura 8) tonifica os glúteos e aumenta a flexibilidade da articulação coxofemoral; vesícula biliar 30 (Figura 8) mestre das coxas e promove a flexibilidade para o movimento dos membros inferiores; pulmão 1 (Figura 7) mestre dos pulmões promove o trabalho respiratório eficiente; bexiga 17 (Figura 7) mestre do dorso, shu dorsal do diafragma e ponto de influência do Xue que regulariza o ritmo respiratório; triplo aquecedor 15 (Figura 7) mestre dos braços que comanda o grupo músculo articular dos ombros, nuca, da coluna cervical, das seis primeiras vértebras torácicas, dos braços, antebraços, punhos e da mão.

Os resultados identificaram uma melhora significativa, com diminuição do tempo na segunda bateria dos testes de 100 metros. A média de melhora nos tempos foi de $5,72 \%$ e o atleta com melhor performance alcançada atingiu um percentual de $10,84 \%$.

Esta média de 5,72\% alcançados na melhora do desempenho parece pequena, mas se compararmos com resultados de competições importantes, observa-se a validade da prática: nos Jogos Pan-americanos do Rio de Janeiro de 2007, na final dos 100 metros raso masculino a diferença entre $01^{\circ}$ colocado e o $8^{\circ}$ foi de 0,23 segundos, representando um tempo de 2,26\% maior, ou seja, se este atleta obtivesse uma melhora de $5,72 \%$ na sua performance, provavelmente conseguiria outros resultados.

Há pouca atenção científica, quando se tratamos, de efeitos da acupuntura em melhoras da resposta fisiológicas induzida pelo exercício e poucas direcionadas para atletas de alto rendimento. ${ }^{24,38}$ Mas Rossetto ${ }^{31}$ apresenta um protocolo para melhora do desempenho atlético no futebol e rugby utilizando os seguintes pontos: bexiga 52 e bexiga 58 (Figura 8); bexiga 17 e pulmão 1 (figura 7).

O ponto bexiga 58 , tonifica a musculatura estriada de todo o corpo, articulação dos joelhos, tornozelos e pés. É um ponto importante para evitar a fadiga, principalmente se utilizado com o Estômago 36 . O bexiga 17 tonifica os músculos dorsais, os 
ligamentos articulares e ainda aumenta a flexibilidade das próprias articulações vertebrais, promovendo ação reguladora sobre o diafragma, o ritmo respiratório e os nervos frênicos. $O$ bexiga 52 tonifica toda a região dos músculos lombares e promove a força de vontade. O pulmão 1 é utilizado para que o trabalho respiratório seja eficiente e está relacionado aos nervos supraclaviculares e intercostais (com inserção mais profunda) auxiliando no plexo braquial. Utilizando com o ponto bexiga 17 regulariza o ritmo respiratório.

Assim como Bopp Limoge ${ }^{39}$, aplicou um protocolo de três pontos fixos: fígado 5 (Figura 10), triplo aquecedor 15 (Figura 7) e bexiga 58 (Figura 8), somados a dois outros pontos aleatórios, placebo, em 35 atletas, obtendo melhora significante da performance atlética dos indivíduos testados.

Figura 10: fígado 5 - 5 tsun acima do maléolo medial; na borda póstero-medial da tíbia.

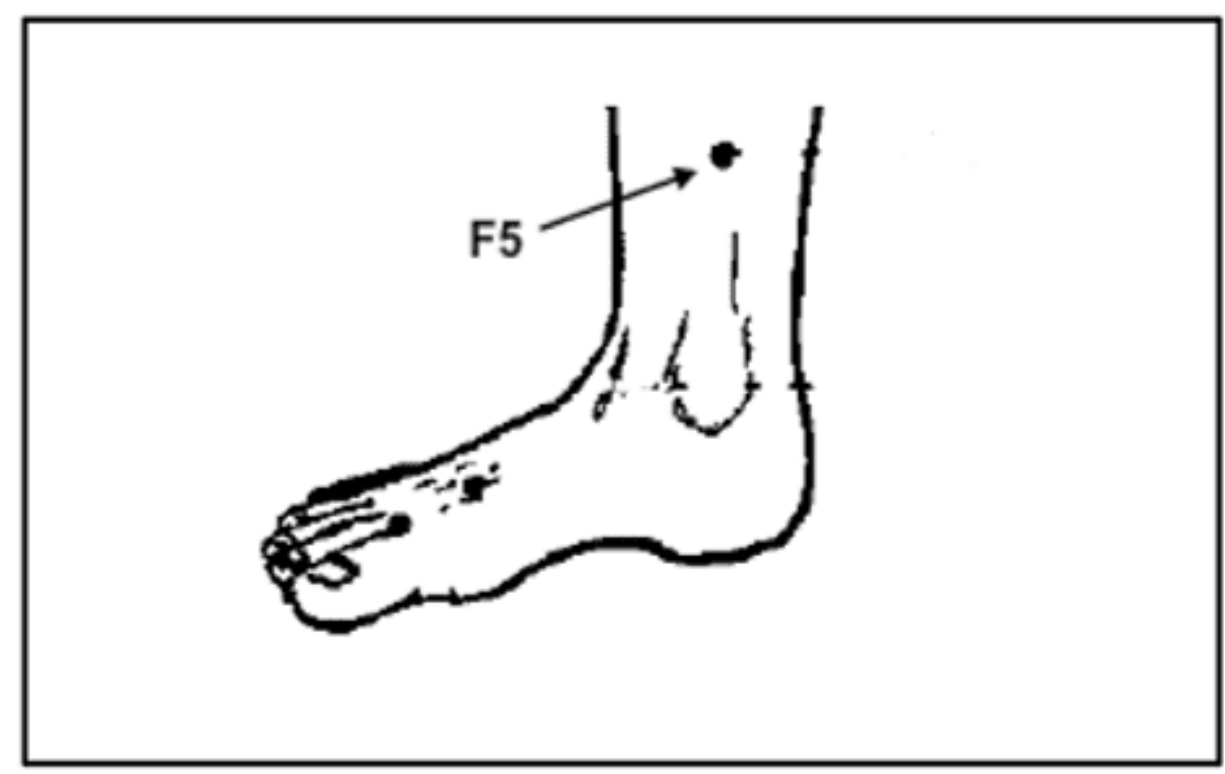

Fonte: Wen ${ }^{17}$

O estudo de Akimoto ${ }^{38}$, corrobora com os resultados de várias pesquisas relacionadas com a melhora da capacidade física e mental, onde testou vinte e uma atletas de futebol, durante a fase de competição, avaliando bioquimicamente o $\lg \mathrm{A} \mathrm{e}$ cortisol salivares, por taxa de tensão muscular e fadiga, resultando no aumento do 
cortisol e baixa de IgA salivar, confirmando a eficaz na melhora do desempenho atlético e mental.

Em outra pesquisa realizada no tratamento de lesões esportivas com acupuntura cinética (associação de acupuntura com cinesioterapia), em atletas de tênis, futebol, vôlei, ginástica olímpica, capoeira, bale e jiu-jítsu; portadores de distúrbios locomotores como: tendinite do tendão de Aquiles, lombalgia, dorsalgia, torcicolo, tenossinovite, síndrome do túnel do carpo, síndrome do pronador, contusão muscular, tennis elbow e gonalgia por lesão de menisco. Todos os 31 atletas testados retornaram aos treinamentos, no máximo, até a terceira sessão: 53\% retornaram após a primeira sessão; $37 \%$ após a segunda; $11 \%$ após a terceira, concluindo que esta técnica atuou de forma eficiente acelerando o tempo de recuperação dos atletas. A explicação para isto é que a acupuntura atua na inibição do ciclo espasmo - dor, levando a um bloqueio aferente segmentar, bloqueio descendente supra-espinhal, mediante as vias piramidais e ativação do processo analgésicos endógenos. ${ }^{26}$

Em outro estudo foi avaliado as variáveis de força máxima, força explosiva, resistência anaeróbica e velocidade nos corredores velocistas de alto rendimento, durante um período de transição. Foi enfocado o meridiano do fígado: fígado 1; fígado 3; fígado 8 (Figura 11A), pois as funções energéticas deste órgão são armazenar o sangue, controlar a dispersão, drenagem e determinar as condições dos tendões e ligamentos, além de controlar a parte emocional, pois um déficit energético pode desencadear: depressão; irritabilidade; insônia; sonhos perturbadores. O primeiro acuponto punturado era o bexiga 62, vesícula biliar 34, rim 3 (Figura 11B), seguidos do baço pâncreas 3 (Figura 1A), fígado 1, fígado 3, fígado 8 (Figura 11A), estômago 36 (Figura 1B) e fechando com o intestino delgado 3 (Figura 3B). Os pontos do fígado foram introduzidos na oitava sessão. Os resultados foram positivamente impactantes, desenvolvendo uma melhora nas funções estudadas. ${ }^{24}$

Figura $11 \mathrm{~A}$ : fígado 1 - 0,1 tsun acima do ângulo lateral do leito ungueal do dedão do pé e fígado 3 - entre o primeiro e o segundo metatarsos, atrás das articulações metatarso-falangeais; fígado 8 - no fim do lado medial da prega poplítea, na borda ântero-medial dos músculos semimembranoso e semitendinoso. B: rim 3 - entre a 
borda posterior do maléolo medial e o tendão de Aquiles; vesícula biliar 34 - I tsun abaixo do joelho, na depressão anterior e inferior da cabeça da fíbula, na fáscia do músculo perôneo longo; bexia 62 - 0,5 tsun abaixo do maléolo externo, na depressão inferior do maléolo.

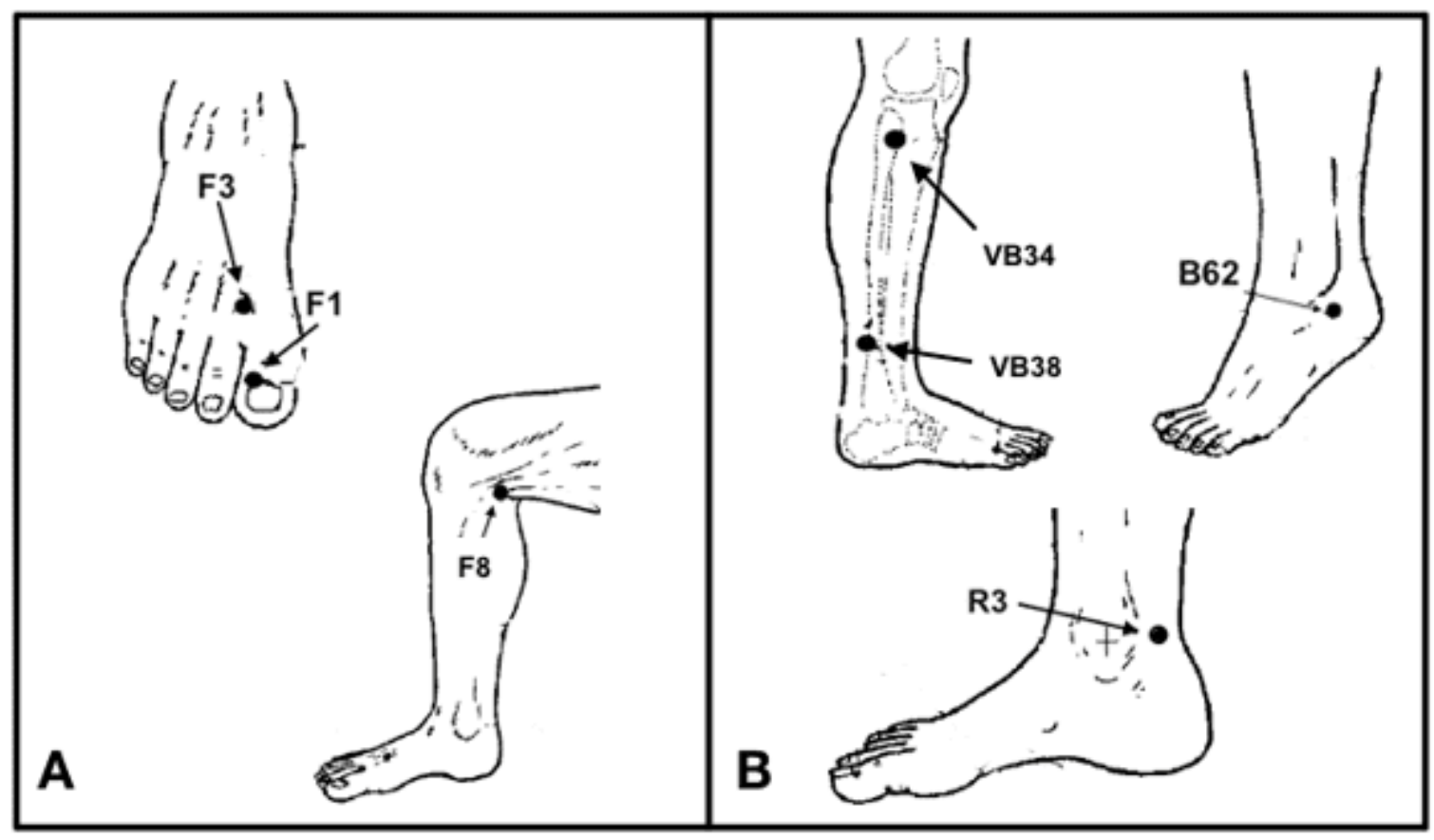

Fonte: Wen ${ }^{17}$

Já Ehrlich ${ }^{25}$, dividiu 36 indivíduos do sexo masculino, em três grupos: um tratado com acupuntura sistêmica; outro grupo controle; outro com acupuntura placebo. Obtevese uma melhora significativa na performance física e nos parâmetros hemodinâmicos. Foram realizados uma sessão por semana nos pontos vaso governador 20 , vaso concepção 15 e fígado 13, bexiga 43 (Figura 12), estômago 36 (Figura 1B) e baço pâncreas 6 (Figura 1A) por 5 semanas. Analisaram que o limiar anaeróbico melhorou em $6,62 \%$ e a performance máxima em $7,15 \%$ no grupo que recebeu acupuntura sistêmica, já no grupo controle e placebo, não houve alterações.

Figura 12: vaso governador 20 - na linha centro-vertical da cabeça; 7 tsun acima da borda posterior do cabelo; 5 tsun atrás da margem anterior do cabelo; vaso concepção 15 - 3 tsun acima do Zhongwan (RM12), na linha central do abdômen e fígado 13 - na borda inferior do ponto final da décima primeira costela, no lado do abdômen; bexiga 
43 - 3 tsun, lateral da linha central (Du-Mai), no nível da borda inferior da espinha da vértebra (T5).

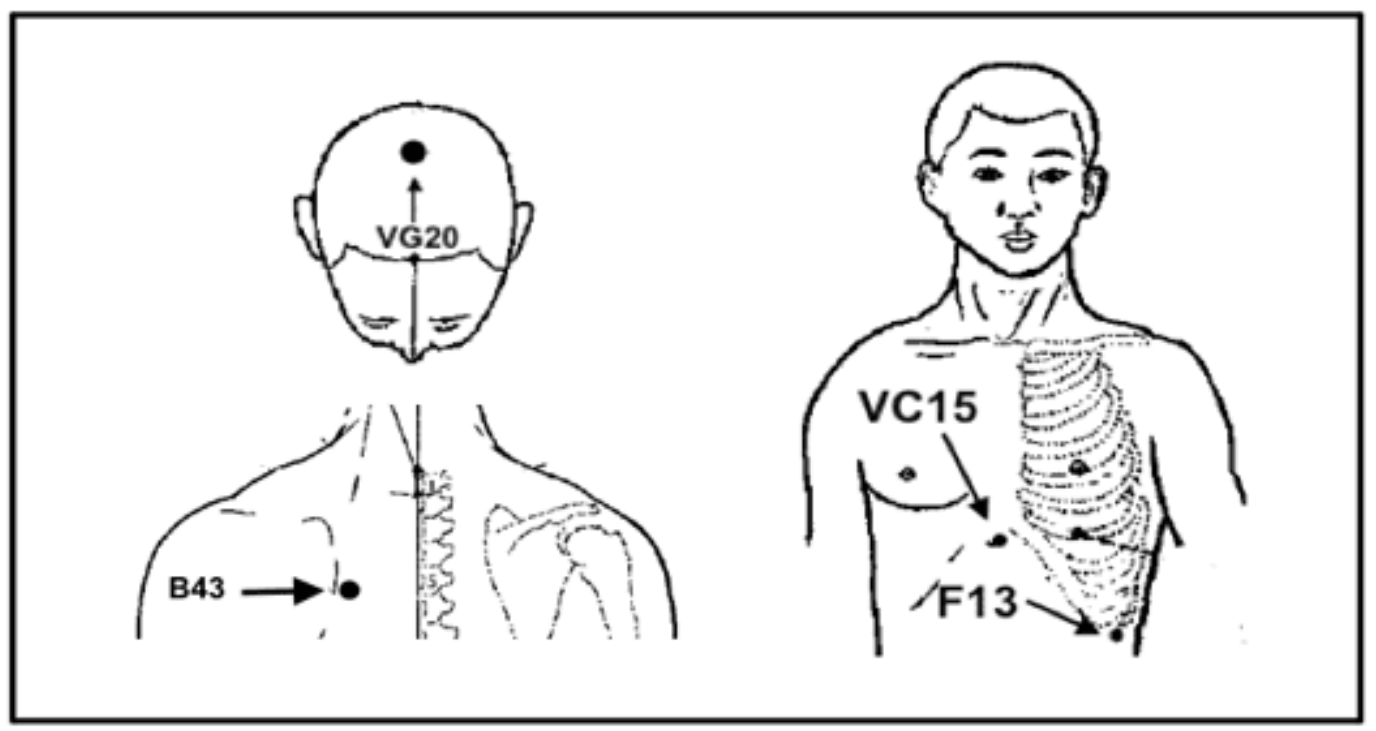

Fonte: Wen ${ }^{17}$

Lin ${ }^{40}$, avaliou os efeitos da acupuntura auricular na frequência cardíaca (FCmáx), consumo de oxigênio (VO2máx) e ácido lático sanguíneo em atletas de elite de basquete. Foram divididos em 2 grupos de 12 atletas cada, onde: Grupo 1 acupuntura auricular; Grupo 2 - controle. Cada um dos atletas pedalaram em bicicleta ergométrica até a exaustão, sendo que a $\mathrm{FCmáx}, \mathrm{VO}^{2}$ máx e ácido lático sanguíneo foram mensurados durante o período de descanso, após aquecimento e durante o exercício: após 5, 30 e 60 minutos. Os resultados apresentaram que a FC e o ácido lático sanguíneo foram significativamente mais baixos do que no grupo controle, após 30 e 60 minutos de atividade.

O mesmo autor, Lin ${ }^{41}$, em uma nova pesquisa, avaliou as mesmas variáveis de FCmáx, VOmáx e ácido lático sanguíneo em 30 atletas de basquete, divididos em 3 grupos: 1- acupuntura sistêmica; 2- grupo sham; 3- controle. No grupo 1 foram utilizados o ponto circulação e sexualidade 6 (Figura 13), estômago 36 (Figura 1B) e durante a pesquisa cada atleta realizou os ensaios em esteira ergométrica por 15 minutos. As variáveis foram mensuradas em descanso e em 5, 30 e 60 minutos após o exercício, obtendo a redução significante das três variáveis após 30 e 60 minutos. 
Figura 13: circulação e sexualidade 6 - 1 tsun abaixo do ponto Jianshi (PC5); 2 tsun acima do punho, entre os tendões dos músculos palmar longo e flexor carpo-radial

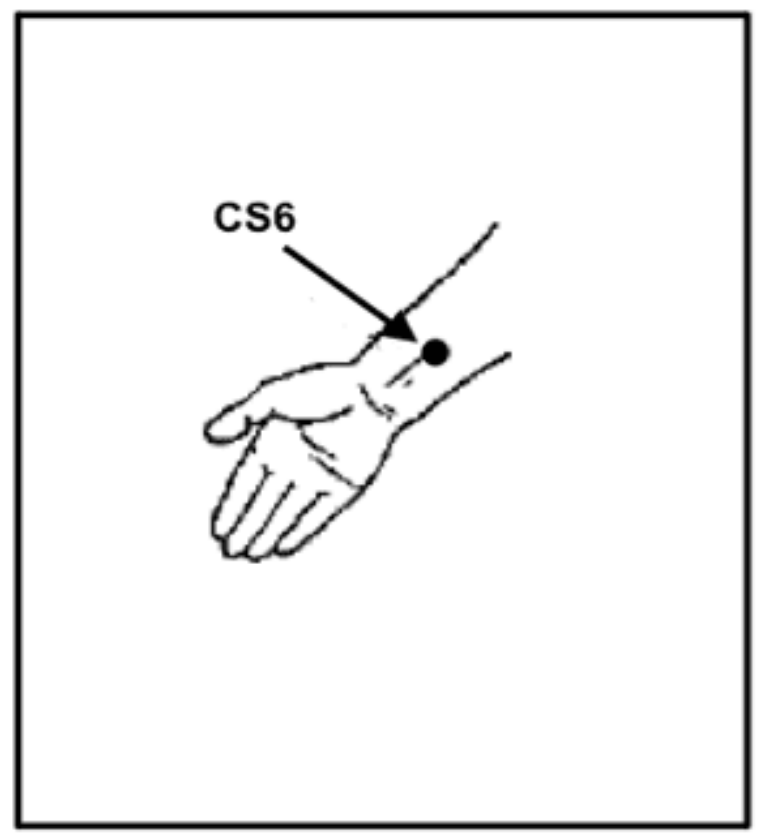

Fonte: Wen ${ }^{17}$

Já Dhillon ${ }^{42}$, avaliou a performance de 20 ciclistas, do sexo masculino, subdivididos em três grupos: tratado com acupuntura sistêmica: estômago 36 (Figura 1B), vesícula biliar 34 (Figura 11B), fígado 11 (Figura 14), rim 3 (Figura 11B), vaso governador 20 (Figura 12); acupuntura sham; controle, sem intervenção. Os atletas pedalaram em bicicleta estacionária por $20 \mathrm{~km}$, na sua velocidade máxima suportada. Foi avaliado a escala analógica de dor, visual, para membros inferiores, induzida pelo exercício; escala de Borg de esforço percebido; concentrações de lactato sanguíneo pós exercício. O grupo induzido a acupuntura apresentou uma pontuação maior na Escala de Borg, significando que o tratamento promoveu um maior esforço durante a atividade e diminuiu o tempo de conclusão da prova. 
Figura 14: fígado 11 - 1 tsun abaixo da ingüinal; na borda ântero-medial do ponto inicial do músculo adutor longo

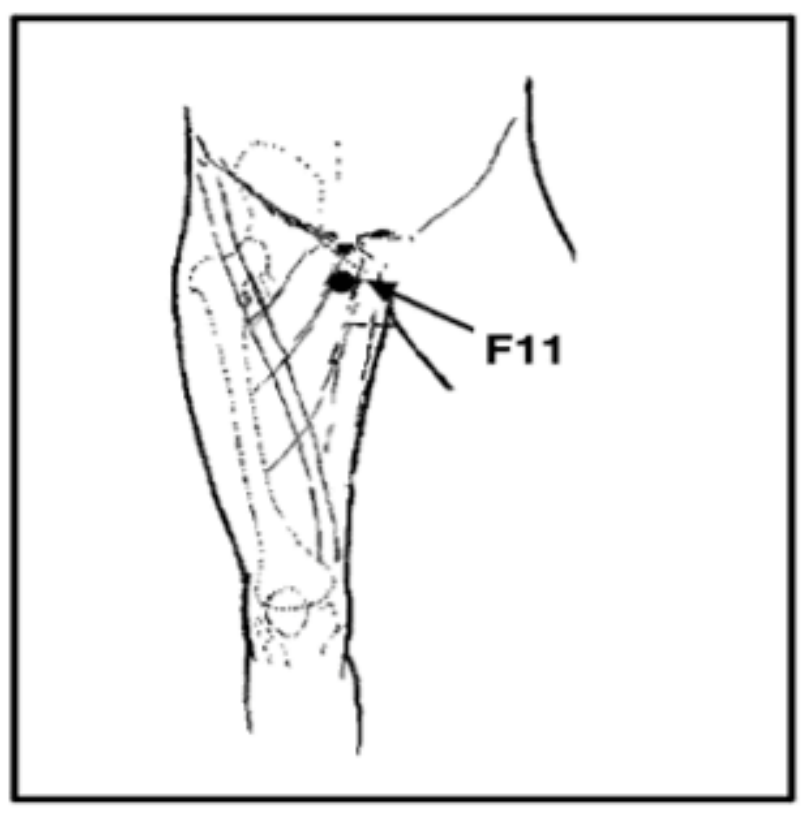

Fonte: Wen ${ }^{17}$

Segundo Hubscher ${ }^{43}$, avaliou o salto máximo com aterrisagem bipodal e força máxima isométrica voluntária do quadríceps, com eletromiografia de superfície para medir a atividade do músculo reto femoral durante 30 segundos de sustentação. Foram divididos 33 atletas indivíduos (13 sexo feminino e 20 masculino) em três grupos: acupuntura sistêmica utilizando os pontos estômago 36 (Figura 1B), baço pâncreas 6 (Figura 1A), vaso concepção 6 (Figura 9); grupo de acupuntura com pontos não existentes; grupo controle utilizado laser desativado. Como resultado encontrado, foi um aumento não significante no salto máximo, mas um aumento importante quanto a força isométrica do quadríceps.

Em outra pesquisa Geng ${ }^{44}$, recrutou 12 homens saudáveis estudantes de educação física, entre 19 a 25 anos, avaliando os efeitos da acupuntura auricular nos níveis de ácido lático sanguíneo, induzido pelo exercício em esteira ergométrica (VO²máx). Escolheu os pontos: Fígado, Pulmão, Subcórtex, Glândulas Endócrinas e Triplo 
Aquecedor (Figura 15). Os resultados foram um aumento na capacitação de oxigênio e diminuição dos níveis de ácido lático sanguíneo pós exercícios.

Figura 15: Pontos Auriculares

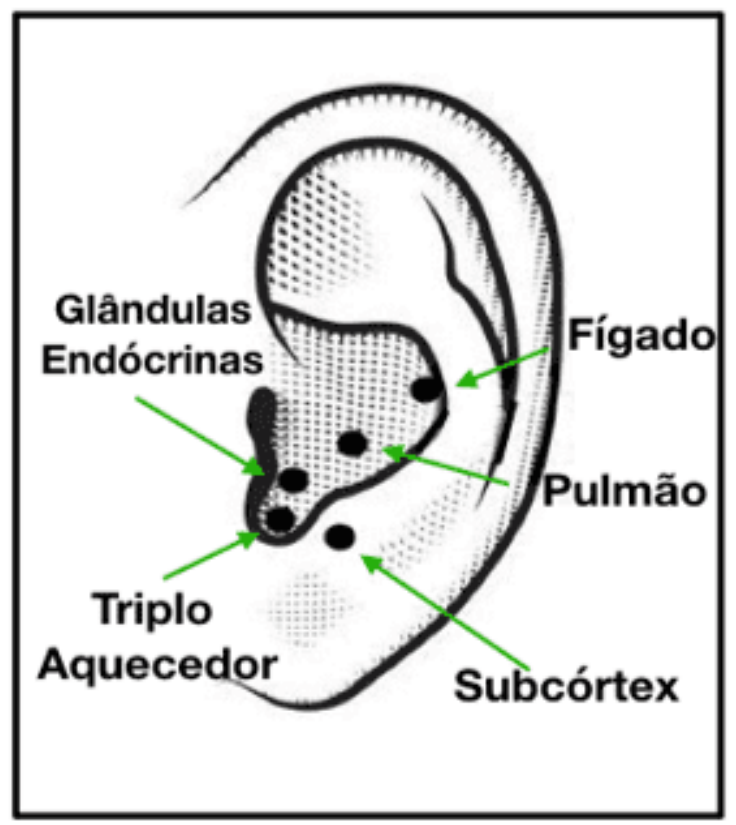

Fonte: Arquivo pessoal do autor

Outro estudo com 28 indivíduos, do sexo masculino, divididos em grupo controle e experimental. Foi realizado uma coleta de dados antes das sessões de acupuntura: Aferição da frequência cardíaca basal, através do oxímetro; aferição da frequência cardíaca após realização do teste físico no Banco de Harvard, com altura de $50 \mathrm{~cm}$, efetuando subidas e descidas durante 5 minutos; frequência cardíaca mensurada em 1 minuto e meio do teste, 2 minutos e meio e 3 minutos e meio; cálculo do Índice de Aptidão física (IAF); média da frequência cardíaca e número de subidas e descidas durante a execução do teste do Banco de Harvard. Foi utilizados os pontos: pulmão 10 e vaso concepção 17 (Figura 16), intestino delgado 3 (Figura 3B), no intuito de tonificar e levar a um relaxamento muscular, fortalecendo os tendões, coluna lombar e membros inferiores. Nos pontos vesícula biliar 34 (Figura 11B), baço pâncreas $4 \mathrm{e}$ rim 7 (Figura 16) foram relacionados a sedação para potencializar a movimentação da circulação do sangue (Xue) e da linfa (Jing Yie). Foram realizadas oito sessões, uma 
a cada semana e os resultados não apresentaram um melhora significativa em relação a frequência cardíaca e aptidão física. Já em o aumento do desempenho físico, subidas e descidas do Banco de Harvard, os valores foram significativos ao grupo experimental em relação ao controle. ${ }^{36}$

Figura 16: pulmão 10 - no lado palmar, acima da junta do primeiro metacarpo digital, entre as peles escura e clara; vaso concepção 17 - na linha medial do esterno no nível do mamilo; rim 7 - 2 tsun acima do Taixi (R3); na borda ântero-medial do músculo sóleo; baço pâncreas 4 - no lado medial do pé; 1 tsun atrás da articulação metatarsofalangeal, na junção da pele escura e clara.

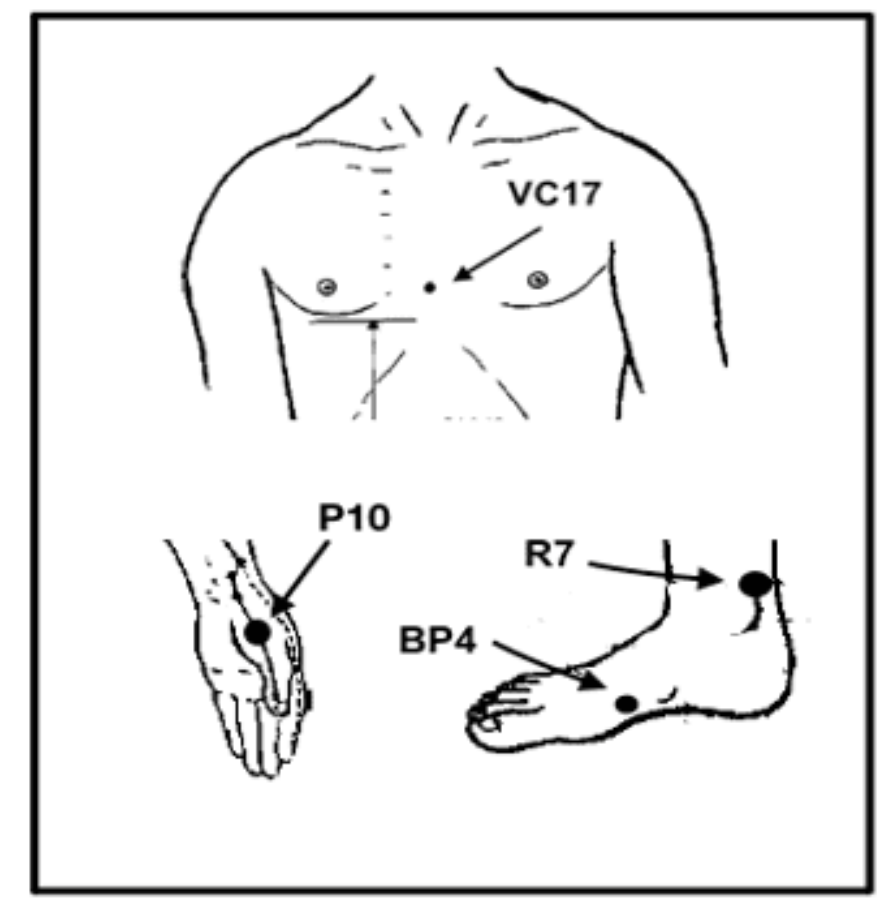

Fonte: Wen ${ }^{17}$

Já Fonseca ${ }^{45}$, utilizou uma amostra com 40 indivíduos do sexo masculino praticantes de musculação dividem dois grupos: controle e intervenção para avaliar os efeitos da acupuntura na resistência muscular localizada (RML) dos membros superiores. $\mathrm{O}$ grupo controle foi submetido ao teste de RML durante 1 minuto, passando por um período de repouso de 30 minutos e após, o teste foi repetido. 
No grupo de intervenção foi aplicado: o teste; repousou por 5 minutos; aplicação da acupuntura, tonificando os pontos: baço pâncreas 3 (Figura 1A); rim 7 (Figura 16); estômago 36 (Figura 1B); vaso governador 4; triplo aquecedor 15 (Figura 7); por 25 minutos. Após aplicabilidade repetiu o teste de RML, resultando na melhora significativa do desempenho muscular do grupo de intervenção.

Em 2015, Moniz ${ }^{9}$, utilizou 12 atletas de Rugby onde foram distribuídos em grupo controle e grupo teste, realizando acupuntura por 20 minutos nos pontos: coração 5 , bexiga 15, bexiga 44 (Figura 17) e circulação e sexualidade 6 (Figura 13). Na segunda sessão semanal eram realizados punturas nos pontos de tensão e pontos gatilhos. Os resultados sugeriram claramente que a aplicação da acupuntura trás vantagens aos atletas sobre os problemas musculares, com a recuperação total a nível da dor e limitação de movimentos antes do jogo posterior a lesão.

Figura 17: coração 5 - no lado ventral e ulnar do antebraço, no lado ulnar do tendão do músculo flexor carpal ulnar; 1 tsun acima do punho; bexiga 15 - no nível da borda inferior do processo espinhal da vértebra (T5), na mesma linha vertical do ponto Feishu (B13); bexiga 44 - 3 tsun, lateral da linha central, no nível da borda inferior da espinha da vértebra (T6).

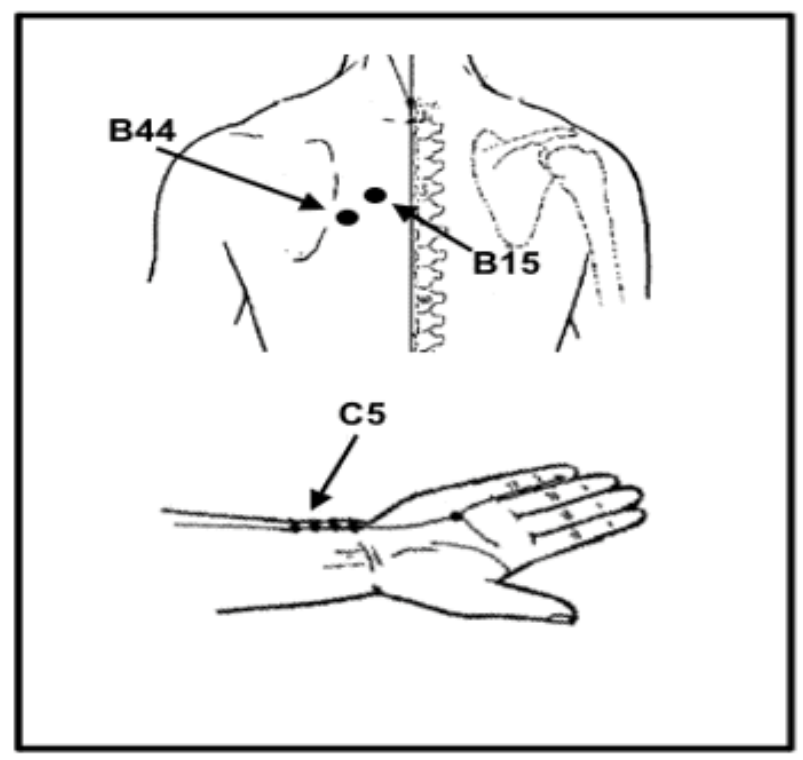

Fonte: Wen ${ }^{17}$ 
A maioria das pesquisas apresentam resultados significativos quanto a melhora do desempenho físico, consequentemente levando a uma melhora no tempo de término das provas. Isto faz com que os indivíduos submetidos ao tratamento da acupuntura, recebam uma ativação da neurofisiologia do controle da dor, desencadeando uma melhora do desempenho muscular, influenciando muito no resultado final. ${ }^{46}$

\section{ACUPUNTURA USADA NO TRATAMENTO DE LESÕES}

A acupuntura atua neste processo de cura da doença, eliminando a sua causa, e desta forma está sendo administrada tanto para tratamento de diversas dores agudas e crônicas. Pode ser utilizada em procedimentos cirúrgicos, na melhora das condições físicas e na prevenção de lesões em diversos esportes. ${ }^{24}$

Atualmente os atletas e seus treinadores buscam a melhora da performance física e a prevenção através de treinamentos exaustivos, acompanhamento nutricional, prevenção fisioterápica, planos de treinamentos, acompanhamento psicológico e utilização de novos equipamentos esportivos atingindo objetivos. Mesmo com estes sistemas aprimorados, muitos atletas preferem e partem para o caminho mais rápido, utilizando o tratamento ilícito, como a utilização de anabolizantes e drogas. ${ }^{32}$ Segundo Frasca ${ }^{35}$, afirma que acupuntura trabalha no ser humano como um todo, tratando a dor, melhorando a performance e agindo diretamente no sistema psicológico dos atletas gerando um aumento da confiança psíquica do desportista.

Segundo Santos e colaboradores ${ }^{20}$, a maioria dos atletas já tiveram a experiência de sentir a dor muscular de início tardio, que aparecem em períodos de treinamentos, onde a intensidade e volume de trabalho são maiores. Outro tipo de dor é ocasionada por uma lesão, afastando o atletas dos treinamentos e competições por longos períodos. ${ }^{21}$

Com base na neurofisiologia, histoanatômicas e neuroquímicas a MTC explica que ao punturar o ponto que está localizado nos canais dos meridianos específicos, irá facilitar o fluxo energético nessas estruturas sobrecarregadas pelas modalidades esportivas, atingindo os objetivos analgésicos. ${ }^{25,47}$ 
Outros autores relatam que a aplicação da técnica tem ação de opióides endógenos, ocorrendo a liberação de â-endorfina que é identificado na modulação da dor e na inibição da transmissão nociceptiva em todos os níveis do sistema nervoso. ${ }^{47}$ Através da utilização da eletroacupuntura ocorre a regulação positiva da expressão da relação da síntese do óxido nítrico neural (nNOS) / NADPH diaforase (NADPHd) bem como o óxido nítrico (NO) no núcleo grácil, mensurado através de vias talâmicas e da medula dorsal. Existem ainda alguns dados que sugerem que além dos opióides, outros mecanismos estão envolvidos no tratamento da dor. 6, 48, 49, 50, 51

A presença de NO favorece a melhora da vascularização local, indicando uma ação homeostástica da acupuntura, mas o aumento de NO no fascículo grácil pode esclarecer esta ação reguladora dos reflexos somáticos causados pela técnica. 6, 52 Outros estudos observam a liberação de serotonina após o estímulo das agulhas. ${ }^{51,}$ 52,53

A acupuntura é aplicada para tonificar, relaxar os músculos dos atletas e manter o equilíbrio energético do organismo. Além do efeito analgésico, é possível estimular outros fatores biológicos, ativando o hipotálamo e a glândula pituitária atingindo efeitos sistêmicos, como: aumento de neuro-hormonios e neurotransmissores. ${ }^{20}$ Sendo assim o efeito de bem estar físico influencia na melhora da performance do atleta em suas respectivas modalidade, desta forma, controlados pelos sistemas, nervoso, endócrino e imune. ${ }^{36,54,55,56,57,58,59,60}$ Muitos estudos revelaram que a acupuntura atua nestes três sistemas, proporcionando: alívio da tensões e dores musculares; aumento do fluxo sangüíneo local; liberação de opioides endógenos, diminuindo a percepção da dor; melhora da modulação do equilíbrio do sistema nervoso simpático e parassimpático; modulação do sistema imunológico; ativação do tecido conectivo e músculos liberando miosinas que possuem efeitos anti-inflamatórios, liberando substâncias antioxidantes, diminuindo o estresse oxidativo; substâncias que tem prováveis efeitos ergogênicos. ${ }^{5,13,61,62,63,64}$

Em um estudo em laboratório, com ratos, Lee e colaboradores, ${ }^{65}$ relataram que o animal quando submetido a acupuntura e ao exercício, apresentou uma supressão dos efeitos sobre a 5 HT (5 hidroxitriptamina) e a expressão de THP (triptofano 
hidroxilase) na rafe dorsal das cobaias, atingindo efeito ergogênico, uma vez que o 5 HT impede a performance do exercício em humanos e ratos.

Em um estudo, Zyloney e colaboradores ${ }^{66}$, relataram que é possível encontrar uma atividade diferente no cérebro, através de avaliação por ressonância magnética, durante o procedimento com as agulhas. Essas alterações aparecem em regiões como: substância cinzenta periaquedural, hipotálamo, córtex somatossensorial primário, giro temporal superior, córtex cingulado anterior rostral e região medial do córtex occipital. ${ }^{48}$

Em sua pesquisa, Minori ${ }^{67}$, tratou lesões por esforço repetitivo do ombro, com a combinação de pontos dos vasos maravilhosos: triplo aquecedor 5 - vesícula biliar 41 (Figura 18) que são utilizados para dores crônicas e intestino delgado 3 (Figura 3B) bexiga 62 (Figura 11B) para dores agudas.

Figura 18: triplo aquecedor 5 - 2 tsun acima da dobra dorsal do punho, entre os tendões do músculo extensor digital comum e o músculo dígito quinto próprio; vesícula biliar 41 - na depressão entre o quarto e quinto metatarsos.

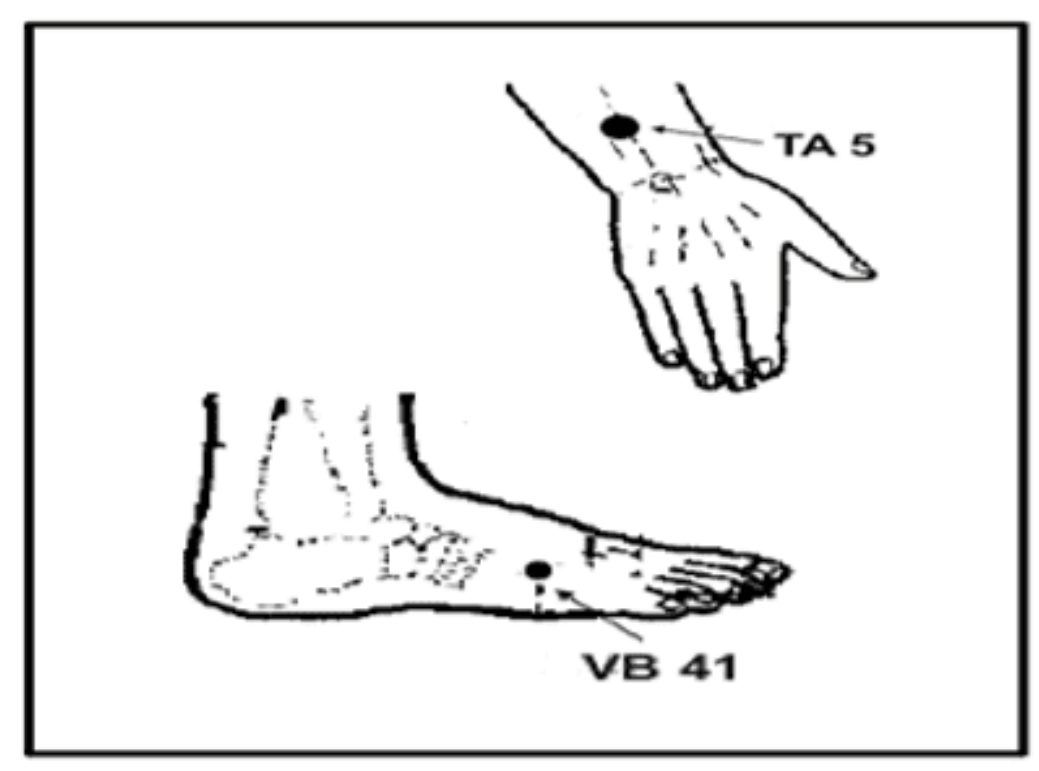

Fonte: Wen ${ }^{17}$ 
Já os pontos locais para tratamento são: intestino grosso 5 para dores no punho; intestino grosso 4 alivia dores e edemas (Figura $4 \mathrm{~A}$ ); intestino delgado 9 dores no braço; triplo aquecedor 14 indicado para dor e inflamação do ombro; intestino grosso 14 (Figura 19) usado para rigidez, paresias, redução da mobilidade do ombro. Os pontos distantes, dor superior e anterior do ombro: estômago 36 para dissipar os fatores patogênicos externos; estômago 37 indicado para dores, distúrbios de sensibilidade e da circulação; estômago 41 elimina a umidade, a estagnação, o vento e acalma o shen (mente); estômago 38 elimina dores agudas e distúrbios da articulação do ombro (Figura 1B). Para dor posterior e superior do ombro: vesícula biliar 34 indicado para redução da mobilidade, espasmos, distúrbios da circulação e distúrbios funcionais dos músculos e tendões; vesícula biliar 38 dispersa o vento e liberta o calor, ativa o meridiano e seus vasos (Figura 11B). Já as dores sobre a escápula: bexiga 65 pacifica e fortalece o espírito, liberta calor e alivia a dor; bexiga 64 suprime os espasmos e relaxa os tendões; bexiga 60 alivia dor e ativa o meridiano e pontos emocionais (Figura $2 \mathrm{~A}$ ); bexiga 18 promove a calma geral e elimina os espasmos (Figura 19) e fígado 8 relaxa os tendões (Figura 11A). 
Figura 19: intestino delgado 9 - na região póstero-inferior da junta dos ombros, no lado pósteroinferior do músculo redondo maior; triplo aquecedor 14 - na depressão entre o acrômico e o tubérculo maior do úmero, na borda do tendão infra-espinhal; intestino grosso 14 - abrange o lado lateral e um pouco do radial do braço, no ponto distal do músculo deltóide, 3 tsun abaixo do ponto Jianyu; bexiga 18 - na mesma linha vertical do Geshu (B17), no nível da borda inferior do processo espinhal da vértebra (T9).

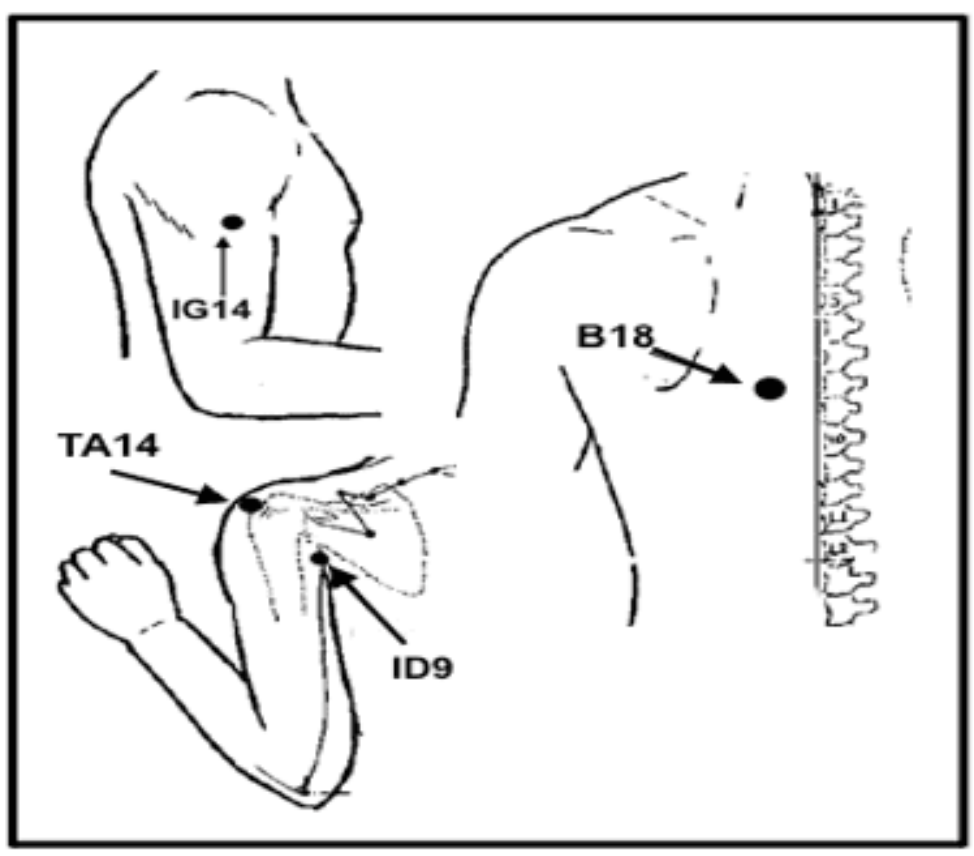

Fonte: Wen ${ }^{17}$

Já Brum ${ }^{68}$, associou em seu estudo para tratamento da síndrome do piriforme, as técnicas de massagem e acupuntura em corredores, a fim de melhorar as funções musculares, flexibilidade e alívio dos sintomas. Integraram a pesquisa os atletas de ambos os sexos com faixa etária de 30 a 60 anos de idade. A sessão se concentrava em massagem (Shiatsu) no início, para liberar os pontos de tensão da região glútea e coxa do lado acometido, seguido de agulhamento, da seguinte forma: sentido horário; anti-horário; aprofundando; superficializando a agulha, nas seguintes regiões: origem e inserção do músculo piriforme (face pélvica do sacro e trocanter maior do fêmur); origem do glúteo médio (face lateral do osso ilíaco); limite superior do glúteo mínimo; 
limite superior do glúteo máximo; origem dos músculos isquiotibiais (tuberosidade isquiática); diáfise do músculo bíceps femoral e do músculo semitendinoso, finalizava com massagem.

Os resultados apresentaram melhora significante, quando relacionado com a melhora da dor, da flexibilidade, da dor a palpação no músculo piriforme e do teste para síndrome do piriforme. Isso mostra a concordância com o estudo de Hongwen ${ }^{69}$, onde a efetividade da acupuntura foi de 97,33\% e com a pesquisa de França ${ }^{26}$ que associou as agulhas com a cinesioterapia alcançando um alívio dos sintomas, a potencialização do sistema neuromuscular, proporcionando um retorno mais acelerado as atividades esportivas.

No seu trabalho, Rocha ${ }^{70}$, verificou a melhora da ativação do músculo reto femoral, através de eletromiografia, após a estimulação do ponto de acupuntura estômago 45 (Figura 20). Foram selecionados 10 participantes (5 do sexo masculino e 5 do sexo feminino), onde realizaram um exercício de 2 repetições de agachamento, onde selecionaram o maior índice de ativação muscular dentre os dois movimentos pelo sinal eletromiográfico. Em seguida foi aplicada a acupuntura, tonificando o ponto estômago 45 por 10 minutos e na sequência foi repetido o agachamento isométrico na fase inferior. De acordo com os resultados encontrados a acupuntura alterou a atividade elétrica do músculo reto femoral durante a fase isométrica na fase inferior do agachamento, mostrando-se eficaz. 
Figura 20: estômago 45 - 0,1 tsun no lado da esquina lateral do leito ungueal do segundo dedo do pé

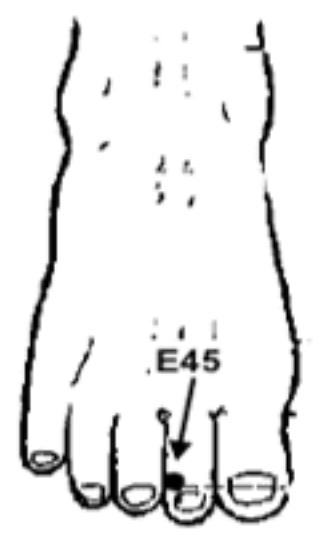

Fonte: Wen ${ }^{17}$

Em outro estudo Pinheiro ${ }^{71}$, caracterizou e protocolou alguns pontos para tratamento de lesão meniscal: fígado 8 (Figura 11A) utilizado para tonificar o canal do fígado com função de harmonizar e tonificar o Qi do fígado e sangue, promovendo a plenitude dos rins e levando ao relaxamento dos tendões e dos músculos, fortalecimento do Qi do joelho. O ponto bexiga 40 (Figura 5) se encontra na fossa poplítea possibilitando: dispersão do calor e vento perverso dos membros; relaxamento dos músculos e dos tendões; desobstruindo os vasos sanguíneos; reduz calor e elimina a estase do sangue; diminuí a regidez e fortalece o joelho e a lombar. Já o ponto rim 10 (Figura 21) mobiliza a água; tonifica o yin Qi; expulsa a umidade e calor perverso, tratando as dores no joelho, edema da perna e entumescimento do joelho e da fossa poplítea. 
Figura 21: rim 10 - no lado medial da prega poplítea, entre os músculos semitendinoso e semimembranoso

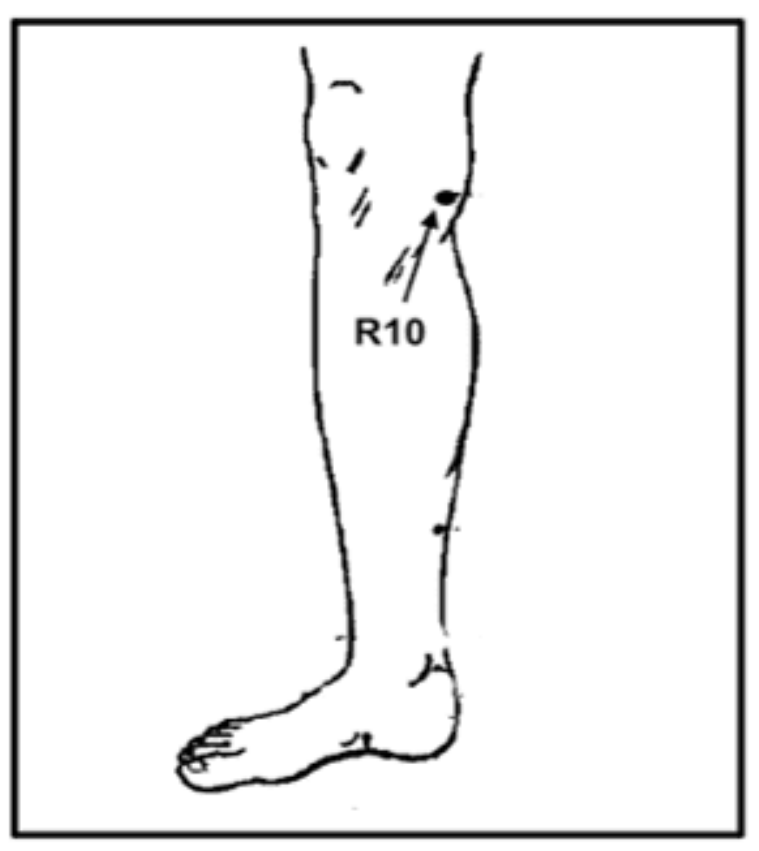

Fonte: Wen ${ }^{17}$

Em um estudo sobre o disfunções no ombro, Nunes ${ }^{72}$, revisou a bibliografia e protocolou os pontos de vasos maravilhosos: intestino delgado 3 (Figura 3B) - bexiga 62 (Figura 11B) para equilibrar as funções, relaxando músculos e tendões; os pontos do triplo aquecedor 5 - vesícula biliar 41 (Figura 18) aliviam a dor e relaxa os tendões; pontos Ashi; fígado 8 (Figura 11A) e rim 7 (Figura 16) para fortalecerem os tendões; estômago 36 (Figura 1B) eliminando frio e a umidade das articulações; intestino grosso 4 (Figura 4A) e intestino grosso 15 (Figura 22) atuando no movimento e na dor da flexão do ombro; triplo aquecedor 14 (Figura 19) e intestino grosso 16 (Figura 22) melhorando a mobilidade de extensão e dor. 
Figura 22: intestino grosso 15 - em cima do ombro, na borda lateral do acrômio, há duas depressões, este ponto fica na depressão anterior; intestino grosso 16 - na depressão entre a borda superior e posterior da junta acrômioclavicular e a espinha da escápula.

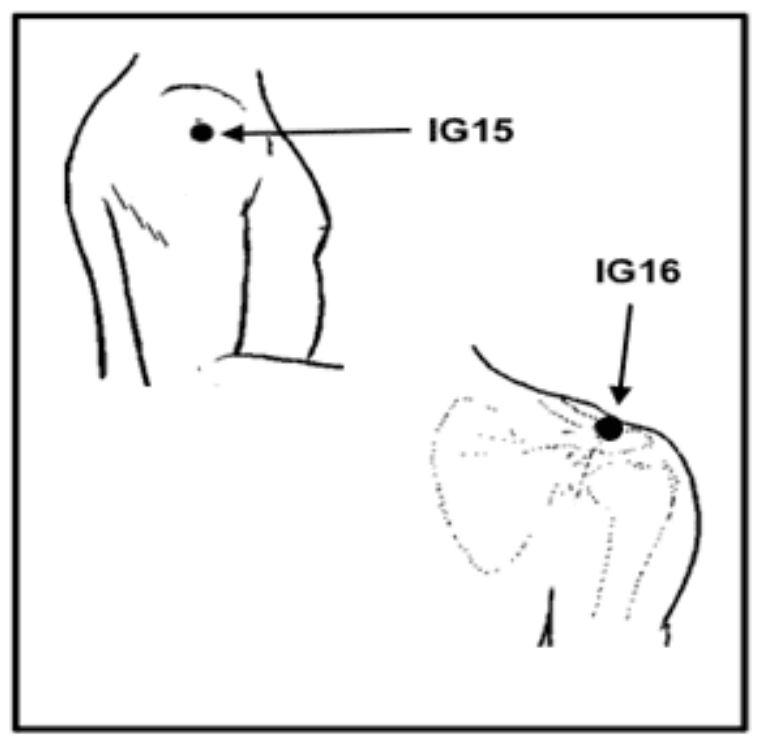

Fonte: Wen ${ }^{1}$

Com intuito de verificar os efeitos imediatos da acupuntura na dor muscular de início tardio (DMIT) e a capacidade funcional contrátil dos músculos, Parisoto ${ }^{73}$, selecionou 30 sujeitos (12 homens e 18 mulheres), com idade entre 20 a 30 anos, praticantes de atividade física, 2 a 3 vezes por semana. Foram divididos em três grupos: tratados com acupuntura; sham placebo; controle. Foram avaliados: limiar de dor com o algômetro; pico de força muscular isométrica máxima; atividade eletromiográfica; percepção subjetiva da dor através da escala visual analógica.

Após as avaliações os voluntários foram submetidos à indução da DMIT, realizando a flexão e extensão do cotovelo com carga (rosca bíceps), até o limite máximo da execução do movimento: foram realizadas 3 séries até a exaustão muscular com um intervalo de 4 a 5 minutos. Após este procedimento foram reavaliados, para mensurar os efeitos da DMIT, ou seja, o estado em que o músculo se encontrava antes da acupuntura. 
Os pontos escolhidos para tratamento do grupo com acupuntura foram: intestino grosso 4 (Figura 4A), intestino grosso 11 (Figura 4B), estômago 36 (Figura 1B), vesícula biliar 34 (Figura 11B), que são pontos analgésicos e tonificantes de músculos e tendões. No grupo sham foram utilizados pontos placebos e as agulhas foram introduzidas superficialmente; grupo controle os indivíduos só ficaram deitados. Ambos os grupos permaneceram por 20 minutos em repouso.

Os resultados apontaram: percepção da dor com a escala analógica foi reduzida no grupo acupuntura; o limiar da dor pelo algômetro aumentou após a intervenção neste grupo. Após a intervenção da acupuntura a ativação do músculo bíceps foi reduzido em $30 \%$ quando relacionados ao grupo sham e controle. A força muscular, após a DMIT, diminuiu $48 \%$ no grupo testado, sendo menor que nos grupos sham e controle (58\% e 56\% respectivamente). Todos os grupos apresentaram déficit de força muscular isométrica máxima após protocolo da indução da DMIT: acupuntura reduziu em $26 \%$; sham $29 \%$; controle $33,5 \%$.

Contudo concluiu-se que a acupuntura foi efetiva na melhora imediata da percepção da dor e no aumento do limiar pelo algômero, proporcionando alterações neuromusculares, mas não melhorando o desempenho contrátil da musculatura.

Em outro estudo Tolentino ${ }^{74}$, avaliou o efeito da auriculoterapia na dor, funcionalidade e mobilidade de indivíduos com dor lombar crônica. Dividiu 31 participantes em três grupos: experimental com agulhas inox descartáveis de $1,5 \mathrm{~mm}$; experimental com sementes de mostarda; controle sem intervenção. Para avaliação da dor foi utilizada a escala visual analógica; para o teste de funcionalidade foi utilizado o questionário de incapacidade lombar de Quebec e o teste de sentado para em pé; para avaliar a mobilidade lombar foi realizado o teste de Schober.

As intervenções foram realizadas por 4 semanas, sendo uma sessão semanal, aplicados nos pontos: Shenmen, Rim, Simpático, Analgesia, Relaxamento Muscular, Coluna Lombar e Adrenal (Figura 10). Após um intervalo de 1 semana após a última aplicação os indivíduos foram reavaliados com o mesmo protocolo. 
Os resultados apresentaram melhora no quadro de dor lombar, bem como a melhora da capacidade funcional em ambos os grupos experimentais, ao contrário do controle que não houve diferença significativa em relação a dor inicial. Não foi encontrado diferença entre as técnicas realizadas (agulha e semente), indicando que ambos são benéficos para alívio de dor lombar crônica e aumento da capacidade funcional.

Figura 23: Pontos auriculares

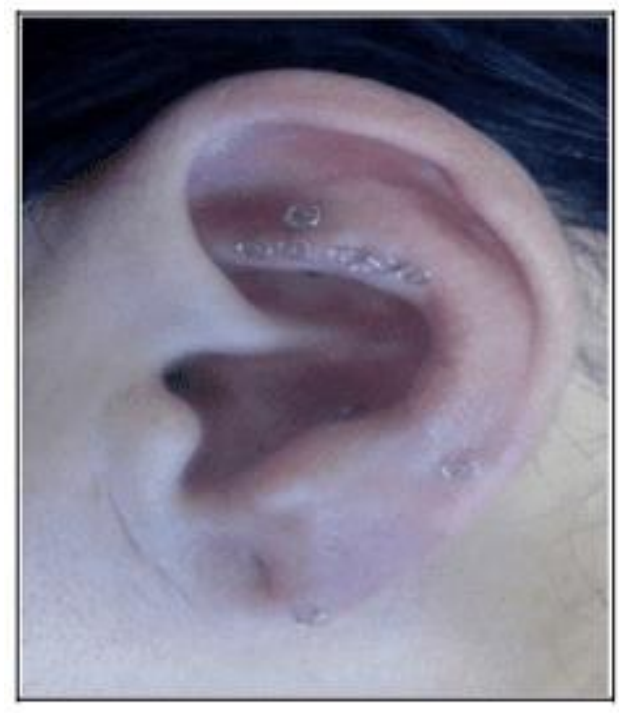

Fonte: Tolentino ${ }^{74}$

\section{CONSIDERAÇÕES FINAIS}

Com base na literatura, analisando todos os resultados e suas evidências científicas, considera-se que o tratamento de acupuntura é efetivo no tratamento, melhora da performance e na prevenção de lesão em atletas profissionais e amadores. Os indivíduos que recebem a intervenção, mesmo que venham apresentar algum tipo de intercorrência lesional, o problema é menos grave e de rápido restabelecimento da função orgânica, ou seja, o atleta que sofrer algum tipo de lesão e estiver realizando acupuntura, esta adversidade tenderá ser mínima e de retorno precoce as atividades.

Mesmo os atletas que não fazem o uso da acupuntura com o intuito de prevenção e apresentam a lesão, a intervenção desta apresenta evidências clínicas, com base na 
neurofisiologia, liberação de opioides, com ênfase no tratamento da dor e melhora do bem estar do paciente.

A intervenção da acupuntura, embora seja uma técnica milenar, ainda está em crescimento no Ocidente, vem desempenhando ótimos resultados na prática clínica, nas questões de prevenção de lesões osteomusculares, e também, na prevenção e tratamento de doenças emocionais, psicossociais, dores agudas e crônicas.

Por equilíbrio do sistema energético, a acupuntura não trata somente o bem estar físico, mas também, o bem estar mental, pois a fundamentação teórica da técnica não separa o corpo da mente beneficiando o estresse emocional, diminuindo a ansiedade e equilibrando a mente humana.

\section{REFERENCIAS}

1. Ching N. O livro de ouro da medicina chinesa. 3. ed. Rio de Janeiro: Objetiva; 1991.

2. Malveira CL, Souza FCS, Rocha TBX. Biomecânica do movimento isométrico de pedala antes e após aplicação de acupuntura: Um estudo preliminar. Motric. 2012 Set;8(52):630-9.

3. Sousa NR. Relação entre a reatividade de pontos de acupuntura e atividade física com afecções ortopédicas determinadas por exames de imagens em equinos. Botucatu. Tese [Doutorado em Biotecnologia Animal] Universidade Estadual Paulista; 2015.

4. Silveira NC, Martins RCC. Eficácia da acupuntura para o tratamento da fibromialgia: Uma revisão sistemática. Psicol e Saúde em Debate. 2018 Fev; 4(1):85-105.

5. Sant' Anna FM, Rangel VM, Mota DDS. Tratamento da Tenossinovite de De Quervain por Acupuntura - Relato de Caso. Vittalle. 2018 Mar; 30(1):130-6.

6. Tsuchiya M, Sato EF, Inoue M, Asada A. Acupuncture enhances generation of nitric oxide and increases local circulation. Anesth Analg. 2007 Feb; 104(2):3017. 
7. Tavares MG, Machado AP, Motta BG, Borsatto MC, Rosa AL, Xavier SP. Electro-acupuncture efficacy on pain control after mandibular third molar sugery. Brz Dent J. 2007; 18(2):158-62

8. Hutchinson AJ, Ball S, Andrews JC, Jones GG. The effectiveness of acupuncture in theating chronic non-specific low back pain: a systematic review of the literature. J Otthop Surg Res. 2012 Oct 30;7:36.

9. Moniz PJL. Avaliação da acupuntura no desempenho do rugby. Coimbra. Dissertação [Mestrado Integrado em Medicina] - Faculdade de Medicina da Universidade de Coimbra; 2015.

10. Magalhães PC. Efeito da acupuntura na prevenção da hemorragia pulmonar induzida por exercício em cavalos puro sangue inglês de corrida. Botucatu. Dissertação [Mestrado em Biotecnologia Animal] - Universidade Estadual Paulista; 2016.

11. Matias $B$ et al. Acupuntura de equilíbrio como coadjuvante no tratamento de disfunções temporomandibulares. Ação Odonto. 2018 Jun; 1(1):65-72.

12. Franco A. Acupuntura Ajuda Atletas nas Lesões e na Performance. Jornal da Madeira 2016 agosto 2;p.25.

13. Lopes SS, Mota MPG. Efeito da acupuntura na resistência física após exercícios repetitivos de tornozelo - Estudo experimental. R bras Ci e Mov. 2018 Jul;26(1):13-21.

14. Lopes SS, Mota MPG. Influência da acupuntura no limiar de percepção dolorosa de musculatura submetida a esforço repetitivo. Br J Pain. $2018 \mathrm{Jul}$; 1(3):207-11.

15. Cohen M, Abdala RJ, Ejnisman B, Amaro JT. Lesões Ortopédicas no futebol, Rev. Bras. Ortop 1997 Dez;32(12):940-44.

16. Dias Junior JC, Marino DM. Acupuntura na prevenção de lesões musculares em atletas de futebol profissional. Rev Fisioter S Fun. Jan-Jul:6(1):36-42.

17. Wen TS. Acupuntura Clássica Chinesa. 15. ed. São Paulo: Cultrix, 2006.

18. Maciocia G. Os fundamentos da medicina chinesa: um texto abrangente para acupunturistas e fitoterapeutas. São Paulo: Roca; 1996.

19. Ross J. Combinações dos Pontos de Acupuntura: A Chave para o Êxito Clínico. 1 ed. São Paulo: Roca, 2003. 
20. Santos VC, Kawano MM, Banja RA. Acupuntura na melhora da performance em atletas juvenis de handebol, Rev Saúde e Pesq 2008 Set-Dez;1(3):331-35.

21. Rubio K, Godoy Moreira F. A dor em corredores com fascite plantar: o uso da acupuntura, Rev Dor 2008 Jul-Set;9(3):1290-1296.

22. Pires TF, Pellegrinotti IL. Acupuntura na Performance Atlética: Estudo Exploratório. [8 8 $^{\mathrm{a}}$ Mostra Acadêmica da UNIMEP; 2010 out; 1-4; Piracicaba, Brasil].

23. Yang HY, Liu TY, Gao M. Electrical acupoint stimulation increases athletes rapid strength, Zhongguo Zhen Jiu 2006 May;26(5): 313-315.

24. Luna MP, Fernandes Filho J. Efeitos da Acupuntura na performance de Atletas velocista de alto rendimento do Rio de Janeiro. Fit e Perform J 2005 Julh/Ago;4(4):199-214.

25. Ehrlich D, Haber P. Influence of acupuncture on pysical performance capacity and Haemodynamic Parameters. J. Sports Med 1992 May;13(6): 486-91.

26. França D, Fernandes-Senna V, Cortez CM. Acupuntura cinética como efeito potencializador dos elementos moduladores do movimento no tratamento de lesões desportivas. Fisioter Bras 2004 mar-abr; 5(2):111-8.

27. Wadsworth L T. Acupuncture in sports medicine. Curr Sports Med Rep 2006 Feb; 5(1):1-3.

28. Barela J A. Estratégias de Controle em Movimentos Complexos: Ciclo Percepção - Ação no Controle Postural. Rev Paul de Educ Fís 2000; 3: 79-88.

29. Papler PG et al. Reabilitação do joelho. In: Greve J.M. A. e Amattuzzi, M.M. Medicina de reabilitação aplicada à ortopedia e traumatologia. São Paulo: Roca, 1999.

30. Gemeo LH. Ignatti C. Acupuntura como Ferramenta Auxiliar do Aumento da Performance Desportiva. In: Anais do Simpósio Internacional de Ciências Integradas da UNAERP; 2004 ; Guarujá, Brasil. São Paulo: Universidade de Ribeirão Preto Campus Guarujá; 2004. p. 1-9.

31. Rossetto SC. Acupuntura nos Esportes. 1 ed. São Paulo: Phorte, 2009.

32. Pelham TW, Holt LE, Stalker R. Acupuncture in human Performance. J Strength Cond Res 2001 May;15(2):266-71. 
33. Myamoto T. Acupuncture treatment for muscle injury. Japa Journ of Phys Fit and Spor Med 1997; 43(2):39-41.

34. Fry AC, Kraemer KJ. Resistance exercise overtraining and overreaching: neuroendocrine responses. Sports Med 1997 Feb;23(2): 106-29.

35. Frasca L. Desempenho na Ponta da Agulha. Rev Farmac 2011 out-nov:44-5.

36. Costa V. Acupuntura Previne Lesões e ajuda a melhorar o Desempenho nas Pistas [periódico na internet]. 2013 [acesso em 22 jan 2017] Disponível em: http://blogs.oglobo.globo.com/pulso/post/acupuntura-previne-lesoes-ajudamelhorar-desempenho-nas-pistas-500798.html.

37. Luna M. Os Benefícios da Acupuntura no Esporte. 2016 [acesso em 22 jan 2017] Disponível em: http://www.ibramrp.com.br/noticia/49/os-beneficios-daacupuntura-no-esporte.

38. Akimoto T, Nakahori C, Aizawa K, Kimura F, Fukubayashi T, Kono I. Acupuncture and responses of imunoligic and endocrine markers during competition, Med Sci in Sports Exerc 2003 Ago;35(8):1296-1302.

39. Bopp-Limoge C. L’acupuncture Permet-elle D`ameliorer les Performances Sportives Stude Personnelle a Propos de 35 Sportifs de haut niveau. These Medicine 1998; 117:215.

40. Lin ZP et al. Effects of acupuncture stimulation on recovery ability for male elite basketball athletes. Amer Jour of Chin Med 2009; 37(3):471-81.

41. Lin, ZP et al. Effect of auricular acupuncture on oxygen consumption of boxing athletes. Chin Med Jour 2009; 22(13):1587-90.

42. Dhillon $\mathrm{S}$ et al. The acute effect of acupuncture on 20-km cycling performance. Clin Jour of Spo Med 2008; 18(1):76-80.

43. Hubscher $\mathrm{M}$ et al. Immediate effects of acupuncture on strength performance: a ramdomized, controlled crossover trial. Euro Jour of Appli Physi 2010; 110(2):353-58.

44. Geng $L J$ et al. Investigation on the effects of ear acupressure on exerciseinduced lactic acid levels and the implications for athletic training. Amer Jour of Acupu 1995; 23(4). 
45. Fonseca LP, Lessa JFM. Efeito da Aplicação da Acupuntura na Resistência Muscular Localizada de Membros Superiores em Praticantes de Exercício Resistido. Brasília. Monografia [Graduação em Fisioterapia] - Centro Universitário de Brasília; 2011.

46. Belmiro H, Vicentini D, Camilotti CM. Efeitos da Acupuntura no Desempenho Motor de Atletas. Rev Fac Educ Fis 2013 jul-set; 11(3):176-91.

47. Angeli AL, Fernandes JGJ, Luna SPL. Acupuncture Applied Equine Sports Medicine, Ver Acad 2007 Jul-Set;5(3):325-33.

48. Staud R. Mechanisms of acupunture analgesia: effective therapy for musculoskeletal pain? Curr rheumatol Rep. 2007 Dec;9(6):473-81

49. Bucinskaite V, Lundeberg T, Stenfors C, Ekblom A, Dahlin L, Theodorsson E. Effects of electro-acupuncture and pysical exercice on regional concentrations of neuropeptides in rat brain, Brain research 1994 Dec;666(1): 128-32.

50. Shang C. Prospective tests on biological models of acupuncture. Evid Based Complement Alternat Med. 2009 Mar; 6(1):31-9.

51. Bowsher D. Mechanisms of acupuncture. In: Filshie J, White A. editors. Medial Acupuncture: a western scientific approach. London: Churchill Livingstone; 1988:69-82.

52. Ma SX. Neurobiology of acupuncture: Toward CAM. Evid Based Complement Alternat Med. 2004 Jun;1(1):41-7.

53. Li J, Wang Q, Liang H, Dong H, Li Y, Ng EH, et al. Biophysical characteristics of meridians and acupoints: a systematic review. Evid Based Complement Alternat Med. 2012;2012793841.

54. Cardeal EL, Oliveira KB, Aoki MN, Amarante MK, Oliveira CEC, Suzuki S, et al. Aspectos imunológicos da acupuntura. Biosaúde 2005 Dez:7(1/2):49-60.

55. Szabó MVRS, Bechara GH. Acupuntura: Bases Científicas e Aplicações. Ciência rural 2001:31(6):1091-99

56. Saad M. A Medicina tradicional chinesa tem base científica?. Einstein: Educ Contin Saúde 2008: 6(3):122-6.

57. Alvarenga TF, Amaral CG, Steffen CP. Ação da acupuntura na neurofisiologia da dor: revisão bibliográfica. Rev Amazôn Scienc \& Helth 2014 Out/Dez:2(4):29-36. 
58. Pereira FAO. Evidências científicas da ação da acupuntura. Perspectivas 2005 jan/jul:4(7):88-105.

59. Taffarel MO, Freitas PMC. Acupuntura e analgesia: aplicações clínicas e principais acupontos. Ciênc Rural 2009 Dez:39(9): 2665-72.

60. Lopes LF, Lopes MC, Fialho FAP, Gonçalves AL. Sistema de conhecimento para diagnóstico em acupuntura:uma modelagem usando o CommonKADS. Gest Prod 2010 Dez:x(x):1-15.

61.Zhu J, Arsovska B, Kozovska K. Acupuncture treatment for sports injury hamstring muscles group, Inter J Clin Exper Med Sci 2017 Nov;3(6):71-3.

62. Vickers AJ, Cronin AM, Maschino AC, Lewith G, MacPherson H, Foster NE, et al. Acupuncture for chronic pain individual patient data meta-analysis, Arch Intern Med 2012 Oct;172(19):1444-53.

63. Toda S. Effect of acupuncture on carnitine for skeletal muscle fatigue, Chin Med 2012 Jan;3:9-12.

64. Lopes SS, Mota MPG. Influência da acupuntura no limiar de percepção dolorosa de musculatura submetida a esforço repetitivo, $\mathrm{Br} J$ Pain 2018 julset;1(3):207-11.

65. Lee, SH, Chung, SH, Lee, JS, Kim, SS, Shin, HD, Lim, BV, et al. Effects Acupunturaq on the 5-hydroxytryptamine synthesis and tryptophan hydroxylase expression in dorsal in the dorsal raphe of exercice rats. Neurocienses Letters 2002 Oct;332(1): 17-20.

66. Zyloney CE, Jensen K, Polich G, Loiotile RE, Cheetham A, LaViolette PS, et al. Imaging the functional connectivity of the Periaqueductal Gray during genuine and sham electroacupuncture treatment. Mol pain. $2010 \mathrm{Nov;6:80}$

67. Minori AET, Mejia DPM. Atuação da Acupuntura para o Tratamento de LER/DORT no Ombro. Goiânia. Monografia [Pós Graduação em Acupuntura] Faculdade Ávila; 2007.

68. Brum KN, Alonso, AC, Brech GC. Tratamento de massagem e acupuntura em corredoresrecreacionais com síndrome do piriforme. Arq Cienc Sau 2009 abrjun; 16(2): 62-6.

69. Hongwen S. Clinical Observation on Acupuncture Treatment of Piriformis Syndrome. J Tradit Chin Med. 2003 mar; 23(1):38-9. 
70. Rocha TBX, Vilela Junior GB, Martins GC, Manzatto L, Grande AJ. Análise Comparativa Eletromiográfica do Reto Femoral em Isometria na Posição Inferior do Agachamento Wall Slide, antes e após a Aplicação da Acupuntura no Ponto ST45. Rev Bras Cien e Mov 2012 jul; 20(4):92-8.

71. Pinheiro RG, Mejia DPM. Efeito da Acupuntura na Melhora do Paciente com Quadro Álgico de Lesão de Menisco Medial. Goiânia. Monografia [Pós Graduação em Acupuntura] - Faculdade Ávila; 2012.

72. Nunes EA, Mejia DPM. Tratamento de Acupuntura para Combater Dores nos Ombros. Goiânia. Monografia [Pós Graduação em Acupuntura] - Faculdade Ávila; 2012.

73. Parisotto D. Efeito Imediato da Aplicação da Acupuntura na Dor Muscular Tardia e na Capacidade de Contração Muscular. Curitiba. Dissertação [Mestrado em Fisiologia] - Universidade Federal do Paraná; 2014.

74. Tolentino F. Efeito de um Tratamento comAuriculoterapia na Dor, Funcionalidade e Mobilidade de Adultos com Dor Lombar Crônica. Rio Claro. Dissertação [Mestrado em Desenvolvimento Humano e Tecnologias] Universidade Estadual Paulista - UNESP; 2016.

Enviado: Abril, 2019.

Aprovado: Outubro, 2019. 